\title{
Scalable Microgrid Process Model: The Results of an Off-Grid Household Experiment
}

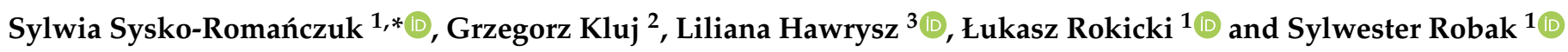 \\ 1 Warsaw University of Technology, 02-524 Warsaw, Poland; lukasz.rokicki@ien.pw.edu.pl (Ł.R.); \\ sylwester.robak@ien.pw.edu.pl (S.R.) \\ 2 PGE Dystrybucja S.A., 04-470 Warsaw, Poland; grzegorz.kluj@pgedystrybucja.pl \\ 3 Wrocław University of Science and Technology, 50-370 Wrocław, Poland; liliana.hawrysz@pwr.edu.pl \\ * Correspondence: sylwia.sysko.romanczuk@pw.edu.pl
}

Citation: Sysko-Romańczuk, S.; Kluj, G.; Hawrysz, L.; Rokicki, Ł.; Robak, S. Scalable Microgrid Process Model: The Results of an Off-Grid Household Experiment. Energies 2021, 14, 7139. https://doi.org/10.3390/en14217139

Academic Editor: David Santos Martín

Received: 30 August 2021

Accepted: 21 October 2021

Published: 1 November 2021

Publisher's Note: MDPI stays neutral with regard to jurisdictional claims in published maps and institutional affiliations.

Copyright: (c) 2021 by the authors. Licensee MDPI, Basel, Switzerland. This article is an open access article distributed under the terms and conditions of the Creative Commons Attribution (CC BY) license (https:// creativecommons.org/licenses/by/ $4.0 /)$.
Abstract: The security of national energy systems as well as the transition to a low-carbon future are two hot topics of discussion in the international political arena. Research on the stability of centralized energy systems is currently focused on distributed generation. Developing a scalable microgrid model enabling its massive adoption is one of the safest and feasible ways to solve such problem. The paper aims to fill an existing gap regarding the operation model of microgrids that is a barrier for the large-scale integration of those in the conventional grid network. In the proposed approach the authors identified key processes to be considered when operating microgrids, in the conditions shown through an experimental (simulation) campaign. A three-phase research was performed: (1) systematic literature review to explore the management models of a stand-alone microgrid design and management; (2) a household experiment; and (3) a computer simulation of energy balance for a selected household. We identified eight key processes constituting a scalable microgrid: five core processes, two supporting processes, and one management process. Subsequently, we developed a map of these processes obtaining a microgrid process model for massive adoption. The model of processes can be considered as a repeatable pattern of conduct in the creation and maintenance of microgrids, which their future owners can follow. To support our literature findings, we performed an experiment and a computer simulation of three sub-processes of the (re)design of the infrastructure process: (1) wind turbine selection, (2) photovoltaic power plant selection, and (3) energy-storage selection. Results confirm conditional stability of the analyzed microgrid and the need for cyclical simulation exercises until unconditional stability is achieved. In terms of sustainability, to keep the microgrid permanently in a positive energy balance will require the implementation of all key processes.

Keywords: household microgrids; off-grid; processes; management; computer simulation; scalability

\section{Introduction}

Innovative advances in renewable-energy sources (RES) and the accompanying technologies have enabled discussion on solutions alternative to the traditional model of energy market organization. RES has become an option for switching to sustainable energy sources. Generation from distributed renewable-energy sources (DRES) is constantly increasing, which, if properly used, may also have a positive impact on the energy security of countries [1-4].

The integration of DRES into power generation systems has been an active field of research for over many years [5-7]. One example of this integration are microgrids: small power grids with distributed generation, including energy-storage devices [8-10]. Pilot microgrid systems are being developed in various electric power systems. For example, CERTS Microgrid concepts have been demonstrated at the Alameda County Santa Rita Jail in California [11]. The last decade has seen particularly strong emphasis on the study of microgrid models which can ensure engineering and technological microgrid stability and 
are suitable for massive-scale adoption. In addition, households absorb digital technologies of industry $4.0[12,13]$, become more autonomous and smart. It is a fertile ground for massive microgrid adoption and transformation of households from energy users to energy producers and surplus distributors, which calls for relevant business models [3] and a scalable microgrid model.

The adoption of RES energy production technologies in households has been growing year by year, but the number of autonomous microgrids has not increased. The market for RES equipment and associated technologies has been growing, but the number of cooperative relations between the producers has not increased in the long term due to problems with their design, finance (business models), and maintenance [14,15]. Microgrid models are still in the phase of either laboratory experiments or individual implementations [16-18]. Scalability of microgrid projects is a challenge for the players in the traditional energy market.

Currently, literature and management practice provide numerous accounts of engineering and technological processes to be implemented in microgrid design. Apart from a small number of pilot projects related to on-grid microgrid business model development [19-25], there are no verified conceptual process-oriented management frameworks, which could lay the foundation for an operational model of organizing off-grid microgrid business. The more real experiments are conducted, the faster the learning process becomes. It accelerates the dissemination and application of off-grid microgrid solutions creating favorable conditions for its mass adoption. This research gap has not been yet investigated in systematic literature reviews. In the last decade, research interest was rather paid to four main research areas: (1) distributed generation access and control technology, (2) energy management, (3) microgrid modelling and control, and (4) microgrid design and management. Additionally, by examining evidence-based microgrids' practice in predefined laboratory experiment, we fulfilled the proof-of-concept conditions for a new solution validating it as a process model of a microgrid.

This paper presents a scalable microgrid process model, verified by computer simulation, needed for massive adoption of microgrids. Following M. Porter's classification [26], we identified: five core processes, two supporting processes, and one management process. Then, we developed a map of these processes, described the key relationships among them, and ultimately obtained a microgrid process model. To test our model, we performed a computer simulation, adopting a process for (re)design of the infrastructure and its three sub-processes: (1) wind turbine selection, (2) PV power plant selection, and (3) energy-storage selection to verify the energy balance of the model

Following a literature review in Section 2, related to the challenges involved in microgrid design and management, in Section 3 we present our three-phase research framework for designing and implementing the microgrid real-world experiment. Then, in Section 4, we present three main research results: a list of key microgrid processes ensuring its operations in the long term; a map of microgrid processes and, finally, a scalable microgrid process model. The section ends with testing our model. We evaluate and discuss our research results according to the scalable microgrid process model in Section 5. Finally, Section 6 concludes and summarizes the limitations of our research work.

\section{Literature Review}

Currently, microgrid design and management is a leading research area due to the growing number of experiments with microgrid implementation in households [10,27]. Danish et al. proposed a project-management process covering the whole life-cycle of the microgrid project from inception to operation [28]. Aberilla et al. investigating the life-cycle environmental sustainability of small-scale off-grid energy systems confirm the necessity of taking into account the sustainability paradigm already on the microgrid design stage [29].

Sustainability means that a completely renewable-energy-powered stand-alone microgrid with energy-storage systems stabilizes the variable and intermittent renewable-energy resources in a long term. The implementation of this paradigm requires a micro grid process model, 
which is associated with its multi-dimensional investigation to cover engineering, technological, and sustainability (organizational and managerial) aspects of real-world application.

In the systematic analysis of the literature, the following two-step review approach was adopted (see Table 1):

Table 1. Two-step of systematic microgrid literature review approach.

\begin{tabular}{|c|c|c|c|c|c|c|c|c|}
\hline No. & 1 & 2 & 3 & 4 & 5 & 6 & 7 & 8 \\
\hline Process Name & $\begin{array}{l}\text { Developing } \\
\text { Technological } \\
\text { and } \\
\text { Organizational } \\
\text { Infrastructure }\end{array}$ & $\begin{array}{c}\text { (Re)designing } \\
\text { of } \\
\text { Infrastructure }\end{array}$ & $\begin{array}{c}\text { Connecting } \\
\text { New } \\
\text { Sources/Loads }\end{array}$ & $\begin{array}{l}\text { Carrying out } \\
\text { Traffic and } \\
\text { Power Control }\end{array}$ & $\begin{array}{c}\text { Cooperating } \\
\text { with Energy } \\
\text { Market } \\
\text { Entities }\end{array}$ & $\begin{array}{c}\text { Maintaining } \\
\text { Grid } \\
\text { Operations }\end{array}$ & $\begin{array}{c}\text { Developing } \\
\text { Human } \\
\text { Competencies }\end{array}$ & $\begin{array}{c}\text { Sustainable- } \\
\text { Energy } \\
\text { Management }\end{array}$ \\
\hline \multicolumn{9}{|c|}{ Step 1: 10 most quoted papers } \\
\hline [30] & 1 & 2 & 3 & 2 & 0 & 0 & 0 & 1 \\
\hline [31] & 2 & 1 & 2 & 3 & 2 & 1 & 0 & 2 \\
\hline [32] & 2 & 2 & 3 & 2 & 0 & 1 & 0 & 1 \\
\hline [33] & 1 & 2 & 3 & 2 & 1 & 0 & 0 & 2 \\
\hline [34] & 1 & 2 & 2 & 3 & 0 & 1 & 0 & 2 \\
\hline [35] & 2 & 0 & 2 & 3 & 0 & 0 & 0 & 2 \\
\hline [36] & 1 & 1 & 1 & 2 & 2 & 3 & 0 & 3 \\
\hline [37] & 2 & 1 & 1 & 1 & 3 & 3 & 0 & 1 \\
\hline [38] & 2 & 0 & 3 & 2 & 0 & 1 & 0 & 1 \\
\hline [39] & 0 & 0 & 1 & 2 & 3 & 1 & 0 & 3 \\
\hline \multicolumn{9}{|c|}{ Step 2: Experts' choice } \\
\hline [40] & 1 & 1 & 0 & 0 & 0 & 0 & 0 & 0 \\
\hline [41] & 1 & 0 & 1 & 0 & 0 & 0 & 0 & 0 \\
\hline [42] & 2 & 0 & 1 & 0 & 0 & 0 & 0 & 0 \\
\hline [43] & 0 & 1 & 0 & 0 & 1 & 0 & 0 & 0 \\
\hline [44] & 0 & 0 & 0 & 2 & 0 & 0 & 0 & 2 \\
\hline [45] & 0 & 0 & 0 & 0 & 0 & 0 & 0 & 2 \\
\hline [46] & 0 & 0 & 0 & 0 & 0 & 3 & 0 & 0 \\
\hline [47] & 0 & 0 & 0 & 2 & 0 & 0 & 0 & 0 \\
\hline [48] & 0 & 0 & 0 & 0 & 0 & 0 & 0 & 3 \\
\hline [49] & 0 & 0 & 0 & 0 & 3 & 0 & 0 & 0 \\
\hline
\end{tabular}

Note: 0 -no support; 1-low support; 2-medium support; and 3-high support. Source: developed by the authors.

Step 1: Most quoted papers - the 10 most quoted publications related to microgrids in 2000-2020 from WoS database were selected (the quotability of the selected publications falls within the range 562 and 1473-building such citation usually takes 10 to 20 yearsand the quotability of items 8-10 fluctuates around 500, which was taken as the cut-off line) and analyzed for contribution to the types of processes described by us (Appendix A).

Step 2: Experts' choice-10 specialized publications related to microgrid processes from 2015-2020 were selected (during the interviews conducted in the first phase of the research, experts were asked to identify those literature items that had the greatest impact on their way of thinking about processes in a microgrid) and analyzed in terms of supporting the specific microgrid process described by us.

The analysis of research outcomes in the first step indicates the researchers' growing focus on the holistic and process-orientated microgrid model. All publications, although to a different degree, list and describe microgrid processes that are necessary in its design and implementation. However, none of them has inspired us to develop a process model of microgrids. On the other hand, the expert selection shows that, on the periphery of the discussion of microgrids, there are researchers who inquisitively analyze a single microgrid process separately. These publications are not widely quoted, because they lack the holistic approach, favoring in-depth analyses of partial processes. These papers also do not describe a complete microgrid process model.

The hottest topics in experts' discussion include traffic and power control, connecting new sources/loads, maintaining grid operations and sustainable-energy management. Niu et al. discussed two basic models for supplying electric power to inhabitants of remote and less-developed areas, including the power grid expansion mode and the microgrid mode, and proposed a cost accounting model for different power modes [41]. 
Jin et al. developed microgrid optimal dispatch with demand response coordinating both demand and supply sides in a renewable-integrated and storage-augmented microgrid. They achieved an economically viable and system-wide resilient solution, which led to a significant reduction of the amount of energy drawn from the mains supply [46]. In turn, Wouter et al. proposed a solution to address the mismatch in electrical power between electric power supply from photovoltaic systems and household electric power demand [31]. Saffari et al. focused on the study of the strategy of microgrid optimization, established a model of performance optimization, and identified its various limitations [44]. In turn, Wang et al. proposed a solution to difficulties in improving the operational economy and maintaining the power balance under uncertain load demand and with renewableenergy generation. They proposed a multi-objective optimization model, including dayahead coarse scheduling and real-time scheduling for finer adjustments. Researchers in the energy-management area have focused on voltage control or reactive power supply, support services, environmental emissions benefits, reduction in system losses, energy production savings, enhanced reliability, power quality improvement, reduction of demand for combined heat and power, and standby generation [48]. Moreover, Jin X et al. developed communication protocol standards for energy management [45].

The modelling and control of the microgrid enjoys a little less interest and includes developing technological and organizational infrastructure, (re)designing of infrastructure, and cooperating with energy market entities. Pecenak et al., supporting investment decision with designing a low carbon and resilient future grid, adopted two novel approaches: the Forward-Looking model and the Adaptive method [26]. Hirsch et al. distinguished three levels of microgrid control: frequency control, voltage control, and enabling economic and optimized operations for the microgrid [43]. Guo et al. derived the general structure of a home grid energy management system based on smart grids and proposed an effective method of home energy distribution [40].

CEER published in 2019 its conclusion paper on new services and DSOs, identifying grey areas for power system services: storage; direct services to the consumer; data management; telecommunications; and services outside the power sector. The paper concludes that a market-centric approach for the facilitation of services should be used wherever possible, with distribution system operators (DSOs) acting as neutral facilitators of service markets.

Developing human (owner/user) competencies for microgrid design and management in the long term is currently the only process absent from academic or expert discussion.

Current research explores intensively technological solutions to ensure efficient functioning of microgrids. Intensive research is also needed to design organizational solutions and management models of microgrids within a scalable framework. Although technological infrastructure, supported by organizational solutions and management processes, is expected to enable microgrid scalability and sustainable functioning in the long term, the dissemination of microgrids as autonomous solutions that meet energy needs of its owner, will require intensive educational support (a process of developing human competences) nearly absent from the microgrid-related literature, being, after all, an essential element for further development of microgrids.

\section{Materials and Methods}

The research material and data presented in this paper were collected in 2017-2021. The research was carried out in three phases:

- 2017-2018 - Phase I: Exploration of the state of the art and available technological solutions. Key activities: a review of Polish and international literature on microgrid implementation; 15 in-depth interviews conducted with scientific experts representing leading academic centres in Poland and with energy industry experts. Material collected: a knowledge base about technological components used in microgrid design, their parameters, producers, and user feedback; IT tools and measurement infrastructure; key elements and technologies of primary technical infrastructure; 
power system automation standards for microgrids according to specific principles (elimination, restoration, and prevention); algorithms, scenarios, and telecontrol and telesignalling infrastructure enabling various potential scenarios of microgrid operations and infrastructure diagnostics; IT tools for microgrid management; processes in the microgrid - as they are and as they should be (checklist); proportions of controllable to uncontrollable elements, communication, control, and signalling standards in microgrids; solutions for demand management; solutions for building an IT system determining the optimal control of consumers within the overall system, controlling operations of the microgrid, and determining areas of piloted microgrids (potential investors and owners).

- 2019-2020 - Phase II: Real-world experiment and implementation of the infrastructure processes to (re)designing of processes in a selected household microgrid. Key activities: defining the microgrid model and its leader/operator, energy mix covering the demand for power and heat; describing the sub-processes of the infrastructure (re)design process: wind turbine selection, PV power plant selection and energystorage selection; gathering data and carrying out analytical measurements of these sub-processes in selected households. Material collected: standardization of input energy parameters for sustainable power consumption of household buildings; average 24-h and annual energy consumption and its electrical characteristics; analysis of variants of average annual electric power production of selected wind turbine and PV power plants; analysis of variants of energy storage and voltage converter selection; description of identified sub-processes, and development of procedures in the event of sub-optimal selection of the microgrid infrastructure.

- 2021-Phase III: Computer simulation of the established three sub-processes of (re)designing of infrastructure during real-life experiment. To verify the correctness of the selection of microgrid elements, a computer model has been created that considers the power demand profiles developed based on the authors' own measurements for the working day, holiday, and the vacation period when household members are away.

In the first phase of the study, inductive modelling was used. Based on both literature analyses and academic/expert interviews as well as the authors' own experience, key microgrid processes and relations among them were distinguished (inductive model). Then, the sine qua non conditions for a real-world experiment were established. The authors are aware of the limitations of this type of modelling as a research approach. This work is the result of a compromise between striving to describe the phenomenon as close as possible to reality and achieve its maximum simplification. In the second phase of research, the subject of the experiment was selected. The chosen household consisted of a residential building (heated by natural gas) and an outbuilding (unheated). Table 2 shows the inventory of basic appliances of the household. The extent of use of individual devices varied and resulted in variable power demand for the residential building and the outbuilding. Equipment usage varied depending on the time spent by the household members away from home. Big differences in power consumption characterized the individual devices.

The figures on annual electric power consumption in the selected household (based on the readings of the electric power meter) are presented in Table 3. Between 2014 and 2016, energy consumption increased and, in 2017, it started to decrease towards $3027 \mathrm{kWh}$ of annual consumption and 8.7 kWh of average daily consumption in 2019. 
Table 2. Average power consumption in the residential building and outbuildings selected for the case study.

\begin{tabular}{|c|c|c|c|c|}
\hline \multicolumn{5}{|c|}{ Main Building Consumers } \\
\hline Device & Quantity & Power & $\begin{array}{c}\text { Estimated Duration } \\
\text { of Use per Day }\end{array}$ & $\begin{array}{c}\text { Estimated Energy } \\
\text { Consumption per Day }\end{array}$ \\
\hline [type] & [pcs] & {$[\mathrm{kW}]$} & [hrs] & {$[\mathrm{kWh}]$} \\
\hline Fridge/freezer & 1 & 1.10 & 2.50 & 2.75 \\
\hline TV & 1 & 0.10 & 6.00 & 0.60 \\
\hline $\begin{array}{l}\text { Gas boiler controller and } \\
\text { boiler room equipment }\end{array}$ & 1 & 0.07 & 24.00 & 1.68 \\
\hline Desktop computer & 1 & 0.40 & 0.50 & 0.20 \\
\hline Laptop computer & 1 & 0.10 & 2.00 & 0.20 \\
\hline Dishwasher & 1 & 1.60 & 0.50 & 0.80 \\
\hline Food processor & 1 & 2.00 & 0.20 & 0.40 \\
\hline Washing machine & 1 & 2.10 & 0.50 & 1.05 \\
\hline Microwave oven & 1 & 1.10 & 0.07 & 0.08 \\
\hline Electric oven & 1 & 2.00 & 0.05 & 0.10 \\
\hline Coffee maker & 1 & 1.90 & 0.10 & 0.19 \\
\hline Cordless kettle & 1 & 2.00 & 0.05 & 0.10 \\
\hline Lighting (light points) & 36 & 0.01 & 0.50 & 0.18 \\
\hline Iron & 1 & 1.50 & 0.25 & 0.38 \\
\hline Audio equipment & 1 & 0.10 & 0.05 & 0.01 \\
\hline \multicolumn{5}{|c|}{ Main consumers in the outbuilding } \\
\hline [type] & [pcs] & {$[\mathrm{kW}]$} & [hrs] & {$[\mathrm{kWh}]$} \\
\hline \multirow[t]{2}{*}{ Lighting } & 4 & 0.06 & 0.10 & 0.01 \\
\hline & & & Total & 8.71 \\
\hline
\end{tabular}

Table 3. Household average 24-h and annual power consumption.

\begin{tabular}{lcccc}
\hline Year & $\begin{array}{c}\text { Electric Power consumption } \\
\text { 1st Half of the Year } \\
{[\mathbf{k W h}]}\end{array}$ & $\begin{array}{c}\text { Electric Power Consumption } \\
\text { 2nd Half of the Year } \\
{[\mathbf{k W h}]}\end{array}$ & $\begin{array}{c}\text { Annual Power } \\
\text { Consumption } \\
{[\mathbf{k W h}]}\end{array}$ & $\begin{array}{c}\text { Average 24-h Power } \\
\text { Consumption } \\
{[\mathbf{k W h} / \mathbf{d a y}]}\end{array}$ \\
\hline 2019 & 1503 & 1524 & 3027 & 8.7 \\
\hline 2018 & 1664 & 1602 & 3266 & 8.9 \\
\hline 2017 & 1822 & 1626 & 3448 & 9.5 \\
\hline 2016 & 1860 & 1998 & 3858 & 10.5 \\
\hline 2015 & 1722 & 2047 & 3769 & 10.2 \\
\hline 2014 & 1772 & 1819 & 3591 & 9.7 \\
\hline
\end{tabular}

The generation equipment and energy-storage calculation data for 2019 were used (due to the decreasing trend in energy consumption). The changes in power demand were characterized not only by short-term daily variations, but also by long-term annual variations. Therefore, the possibility of island operation was planned and implemented. When connecting a new piece of equipment or replacing the existing one, energy demand and supply under new operating conditions were analyzed anew. Basic household electrical 
characteristics are presented in Table 4. The household in question was an example of typical suburban development.

Table 4. Household electrical characteristics.

\begin{tabular}{|c|c|c|c|c|c|c|}
\hline $\begin{array}{l}\text { Overhead Joint } \\
\text { Fuse Protection }\end{array}$ & $\begin{array}{c}\text { Type of Measuring } \\
\text { System }\end{array}$ & Power Limiter & $\begin{array}{c}\text { Connection } \\
\text { Capacity = } \\
\text { Contracted } \\
\text { Capacity = } \\
\text { Household Peak } \\
\text { Capacity }\end{array}$ & $\begin{array}{l}\text { Internal Power } \\
\text { Line Cable * }\end{array}$ & $\begin{array}{l}\text { Power Cable for } \\
\text { Outbuilding * }\end{array}$ & $\underset{*}{\text { Overhead Feeding }}$ \\
\hline In $=32 \mathrm{~A}$ & Direct meter & $\begin{array}{l}\text { C25A overcurrent } \\
\text { circuit breaker }\end{array}$ & $\mathrm{P}=11 \mathrm{~kW}$ & YDYżo $5 \times 10 \mathrm{~mm}^{2}$ & YKYżo $5 \times 10 \mathrm{~mm}^{2}$ & AsXSn $4 \times 16 \mathrm{~mm}^{2}$ \\
\hline
\end{tabular}

* According to Polish standards. AsXSn cables are used as standard in Poland (and Europe) for overhead power supply of residential buildings.

To describe the sub-processes for the selection of generation equipment (PV panels and wind turbine) and the associated infrastructure (energy storage), average 24-h and annual energy consumption was examined and correlated with daily energy consumption of household electrical equipment (the weekly flow of momentary current and voltage values). Such an approach, although more time consuming, enabled deviation from the generalization necessary to estimate peak loads by means of summer-winter simultaneity factors. Average 24-h and annual energy consumption and instantaneous power consumption were supplemented with wind and insolation characteristics. This enabled the selection of the parameters of the PV power plant, the wind turbine, and the energy-storage facility to fully cover sustainable, short- and long-term electric power demand. Energy storage with appropriate specifications was selected for balancing (installed on the power supply side behind the electric power meter, looking from the power supply side) near the site of electric power supply. This allowed us to control power flows to and from the distribution system operator's (DSO's) network.

In Phase III, simulations of microgrid operation were carried out, which required the development of microgrid computational model in accordance with the following assumptions:

- nominal apparent powers of renewable-energy sources (also called microsources) and energy-storage device are known, as are the minimum and maximum levels of active and reactive output power;

- nominal capacity of the energy-storage device is known;

- active power of the current output of the microsource is calculated based on the specifications of this source (presented later in this article) and the intensity of solar radiation (PV source) or wind speed (wind turbine);

- profiles of electric power consumption for active and reactive power are known, as well as the measurements of solar radiation intensity and wind speed for the simulated period of the microgrid operation;

- calculating the output power of the microsource was assumed that power losses of the electronic power converter, by means of which the source is connected to the microgrid, are equal to 0 ; and

- the efficiency of the energy-storage device is $80 \%$.

The computational model of the microgrid was built using the PowerFactory software, which allows for modeling of specific microgrid elements in a relatively easy way. The advantage of the mentioned software is also the possibility to implement a simple microgrid control logic based on the internal script language DPL. The prepared DPL script, which is an integral part of the microgrid computational model, enabled us, among others, to:

- load the profiles of electric power consumption for active and reactive power, as well as microsources output power profiles for the simulated period of microgrid operation;

- perform load-flow calculation in the microgrid; and

- $\quad$ save the results of load-flow calculations for the simulated period of microgrid operation to an external file for its later analysis. 
The DPL script also made it possible to control the operation of microsources and the energy-storage device, considering the following logic:

- for island (autonomous) operation:

- if generated active power is more than the power demand and the state of charge (SOC) of energy-storage device is 100\%, the microsources will be switched off. The operation of microsources will resume as soon as the SOC of the energy-storage device falls below $100 \%$ or there is no longer surplus generated active power; and

- if generated active power is less than power demand and the SOC of the energy-storage device is less than or equal to the minimum permissible level, the simulation calculation will be interrupted (the microgrid will not be able to cover the power demand).

- for semi off-grid operation:

- $\quad$ if generated active power is more than the power demand and the SOC of the energystorage device is $100 \%$, excess energy will be exported to the distribution network;

- if generated active power is less than the power demand and the SOC of the energystorage device is less than or equal to the minimum permissible level, the missing power will be imported from the distribution network and

- $\quad$ in other cases, the energy-storage device is controlled in such a way as to ensure that the balance of energy exchange with the distribution network is zero.

\section{Results}

In phase I of the research the list of eight key processes was developed [50] and the term "microgrid process" was defined. Since then, we have deepened the analysis and description of the previously identified processes in the long term. The microgrid process is a set of logically related activities using local resources leading to the generation of electric power. The microgrid processes aim to cover users' electric power demand sustainably in the long term. We grouped key processes into core, supporting, and management processes.

Finally, the results of the experimental simulation allowed us for a more complete understanding and operational description of the key processes along with the relations between them to organize and manage the microgrid in a sustainable way:

- $\quad$ Core processes:

1. Developing technological and organizational infrastructure to minimize the impact of new microgrid elements on the electric power grid to which they are connected (reducing the need to expand the power grid); in this process, we analyze reports from owners/users and potential owners/users of the microgrid regarding changes in infrastructure and monitor the micro- and macro-environment to analyze technological and organizational trends that could have an impact in the future. We make decisions on the directions of microgrid development;

2. (Re)designing of infrastructure to analyse and predict the impact of new microgrid elements on the operation of the existing infrastructure and the energy needs of microgrid owners/users in a way that ensures the safety of its operation; in this process, we design new microgrid elements, including simulate the operation of an extensive microgrid to obtain optimal technical and organizational solutions;

3. Connecting new sources/loads, aiming to connect new microsources and associated technologies or change the power capacity of the existing ones to ensure a sustainable long-term balance between supply and demand; in this process, we analyse the possibility of connection/redevelopment of new sources/loads from the implementation side (selection a technology, connection of new infrastructure or rebuilding of the existing infrastructure, setup of an extensive infrastructure for the first time, and conducting tests and operational measurements);

4. Carrying out traffic and power control to supervise sustainable grid operation, such as local power backup in case of supply failure (scheduled emergency) from the DSO's network and bidirectional power flows; in this process, we coordinate works related to the construction and operational maintenance of the microgrid; 
5. Cooperating with energy market entities to develop and continue to improve methods of accounting for new services; in this process, we comply with our obligations towards external and internal energy market entities. We set up operational scenarios for the microgrid.

- Supporting processes:

6. Maintaining grid operation to ensure that microsources and loads function according to the operational schedules; in this process, we maintain continuous and uninterrupted operation of the microgrid infrastructure through periodic assessments of the technical condition and visual inspections;

7. Developing human competencies-continuous education in microgrid infrastructure operation, its control and cooperation with external entities; in this process, we define the criteria for the selection of microgrid employees, and in the case of only one owner, we develop and implement a training program dedicated to handling microgrid processes; and

- Management process:

8. Sustainable energy management to develop mechanisms targeted at meeting the energy needs of microgrid owners/users with microsources' capacity. These mechanisms control the core and supporting processes of the microgrid; in this process, we manage the measurement infrastructure, define the regulation of energy consumption, and supervise the microgrid.

The main criterion for distinguishing microgrid processes is ensuring their continuity by establishing multiple control points. It is such a feature of the processes that ensures the continuity of energy supply on the line-receipt-storage-distribution-recipient and controlled by a stable flow of power and energy of the microgrid operator. This operator will be able to control a large number of power sources (RES) located near the load points and to coordinate their island operation [50]. So, we identified, described, and analyzed activities comprising each process and framed the model of microgrid process organization.

We developed a map of these processes and their associated relations (Figures 1 and 2).

Management process

sustainable energy management

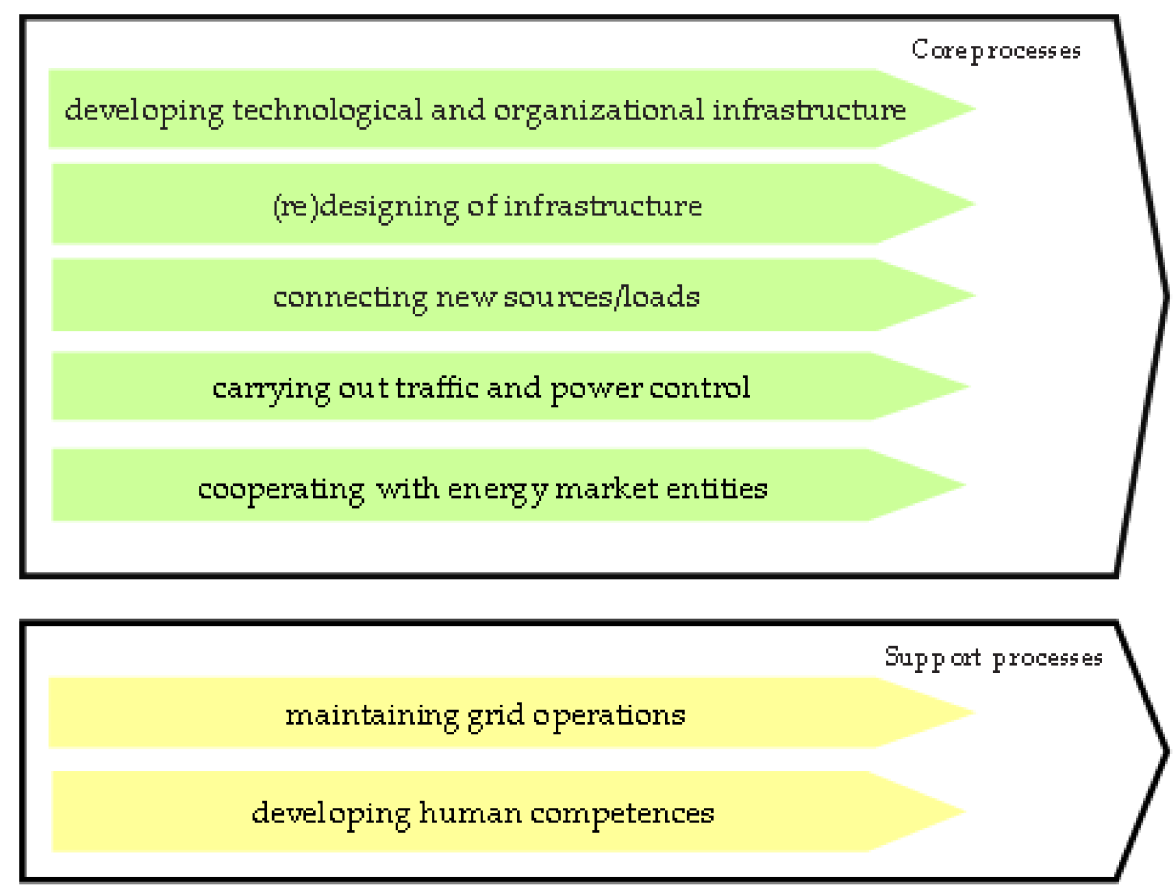

Figure 1. Map of microgrid processes. 


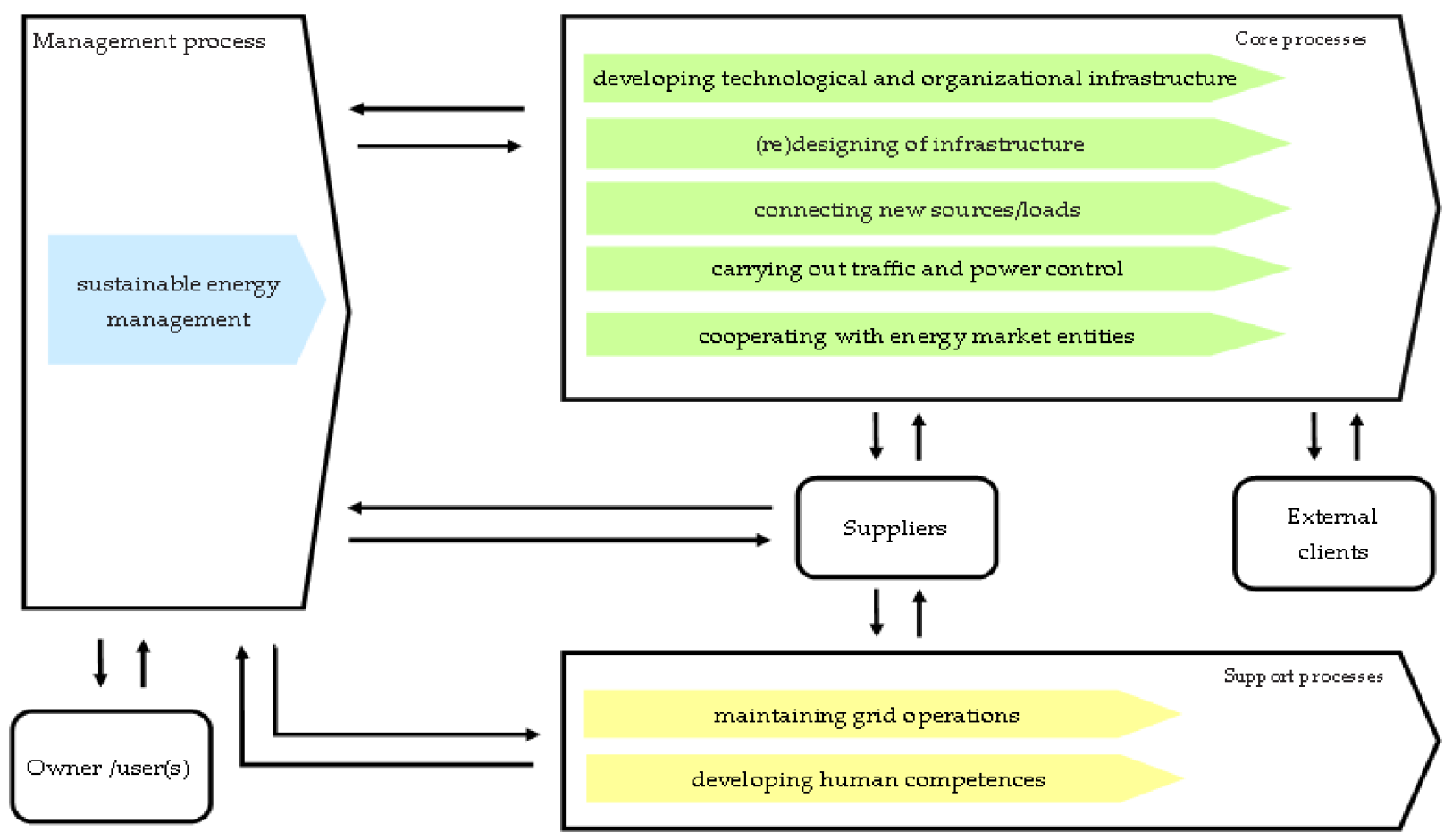

Figure 2. Map of relationships between microgrid processes.

The map of relationships between processes in a microgrid serves to better understand the functioning of the microgrid and how the operation and responsibilities are divided within it, identify discontinuities at the interfaces between processes, and develop a structure to eliminate them. Moreover, that map helps us to evaluate alternative ways of grouping processes. Each process is linked to others by feedback. The owner of the microgrid starts the management process with a decision to establish a microgrid. Aiming at efficient energy management the owner creates the core and supporting processes of a microgrid. The aim of the microgrid is realized in the core processes under the supervision of the management process and cooperation with external stakeholders. They can, for example, buy the excess energy produced in the microgrid by paying an agreed price. All processes require cooperation with suppliers of goods and services to perform efficiently. It would not be possible without the well-described processes of microgrid operation. Regarding the management process, suppliers may deliver new technological expertise. Materials and services for building the microgrid infrastructure are inputs to core processes. Consumables, maintenance, IT support and training for microgrid personnel are inputs to supporting processes. Core processes (end-to-end) involve mainly coordination within the microgrid and with its external clients, aimed at ensuring the energy needs of the stakeholders.

Relationships between the components of the map go in both ways because the exchange of data and information between them is a key requirement for their appropriate implementation and constant improvement. Issuing a command is insufficient; feedback related to the implementation is needed. After implementing a certain number of iterations, an owner takes critical decisions regarding the scope of the microgrid operations. This scope must be aligned with the purpose of microgrid's management process.

A model of the microgrid processes builds on the map of relationships between microgrid processes. The process model of microgrid organization combines processes as multiple linked activities, which help us to better understand the principles of microgrid functioning and the mechanisms of energy balancing within it (see Figure 3). 


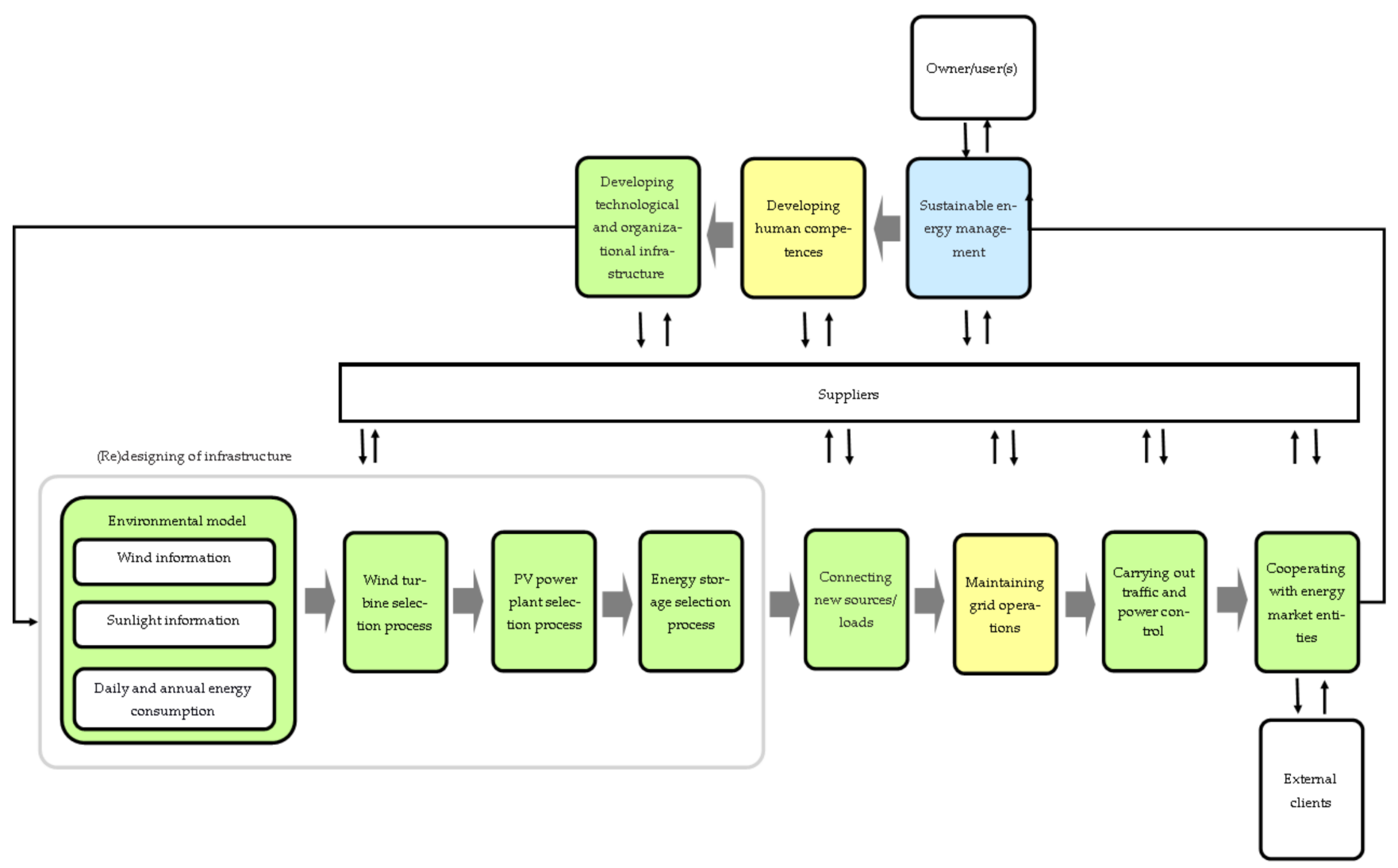

Figure 3. Scalable microgrid process model.

Having decided to build a microgrid, the owner develops a technological and organizational microgrid framework and completes the necessary competencies needed to build a microgrid. Then, the microgrid is designed and eventually connected to the DSO network. After startup, the maintenance process, traffic and power control, and cooperation with external clients are conducted. Figure 3 shows the logic of starting the microgrid model processes in the first iteration.

The model tends to be a general one, but it should not be treated as a ready-to-go solution for any household. Instead, it is intended as an inspiration to create a customized classification of processes adapted to the specific circumstances and needs of a particular household. To mark the situational approach in building the sustainable microgrid, in phase II of our research, we have developed and present below a step-by-step guide for the owner's decision-making framework.

The infrastructure (re)design process begins with the collection of data on local environmental conditions, such as wind and insolation of the microgrid area. The height of the location and length of the mast for a wind microturbine are essential data for determining the parameters of the generating equipment. Therefore, we analyzed the household load profile to calculate the peak power input. Subsequently, we selected wind turbine capacity, type, number of panels and PV power plant, and energy-storage capacity (based on selected wind turbine models, PV panels, and data on energy production capacity of these sources). Adequate capacity of energy storage minimizes power flows to and from the DSO network.

The infrastructure (re)design process consists of three sub-processes, which we analysed in depth with a view to ensuring sustainable microgrid development (long-term operations). We have distinguished the following sub-processes: (1) wind turbine selection, (2) PV power plant selection, and (3) energy-storage selection. Figure 4 shows the subprocess of wind turbine selection. The microgrid area was characterised by average annual wind speeds of 6.35-6.85 m/s 50 m above the ground level (Global Atlas for Renewable Energy/DTU Global Wind Atlas https: / /irena.masdar.ac.ae/GIS/?\&tool=dtu:gwa\&map=103 (accessed on 13 February 2020)). Moreover, this wind zone was considered a favourable 


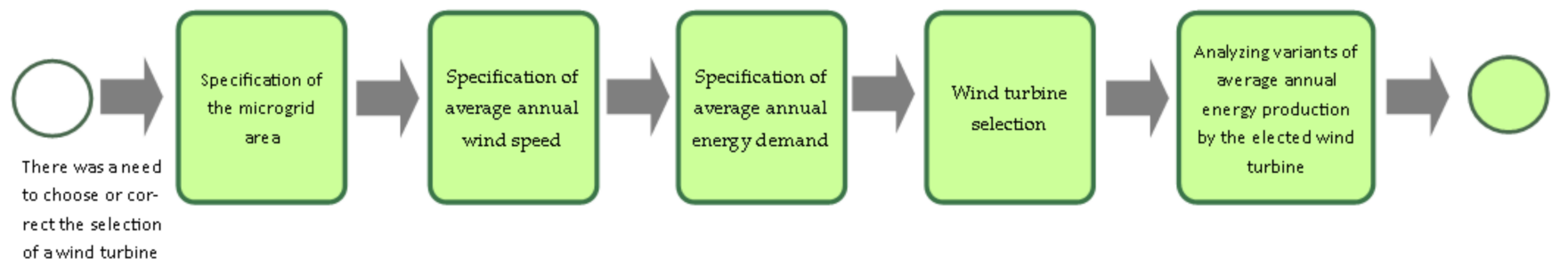

Figure 4. Wind turbine selection process.

In 2019, annual electric power demand of the household was $3027 \mathrm{kWh}$. There is $8760 \mathrm{~h}$ per year. Considering the criteria of the microgrid sustainable development, we selected the microelectric power plant (turbine) to be the IstaBreeze i-2000 stationary solutions mounted on roofs or poles. We analyzed various possibilities of meeting the demand for electric power from wind energy sources. The energy efficiency and power production of the selected wind turbine for average wind speeds are shown in Table 5 (SONET Computers). We calculated average annual electric power production based on power generated (in watts) at a given wind speed. The results indicate that at the average wind speed, it is possible to satisfy the electric power demand of the household with almost double the reserve. In the case of weak wind supply, a half of the energy demand is covered.

Table 5. Energy efficiency and electric power production of the selected wind turbine.

\begin{tabular}{|c|c|c|c|c|}
\hline \multirow{2}{*}{ Wind Type } & \multicolumn{2}{|c|}{ Wind Speed } & \multirow{2}{*}{$\begin{array}{l}\text { Charging Power of } \\
\text { IstaBreeze } \\
\text { i-2000 } 48 \mathrm{~V} \text { in Watts }\end{array}$} & \multirow{2}{*}{$\begin{array}{c}\text { Annual Energy } \\
\text { Produced [kWh/Year] }\end{array}$} \\
\hline & $\mathrm{km} / \mathrm{h}$ & $\mathrm{m} / \mathrm{s}$, & & \\
\hline Calm & $<1$ & $<0.3$ & start & - \\
\hline Breeze & $2-5$ & $0.3-1.5$ & start & - \\
\hline Light wind & $6-11$ & $1.6-3.3$ & 100 & 876 \\
\hline Weak wind & $12-19$ & $3.4-5.4$ & 200 & 1752 \\
\hline Moderate wind & $20-28$ & $5.5-7.9$ & 610 & 5343.6 \\
\hline Fresh wind & $29-38$ & $8.0-10.7$ & 860 & 7533.6 \\
\hline Strong wind & $39-49$ & $10.8-13.8$ & $\begin{array}{l}1600 \text { watts at } 12 \mathrm{~m} / \mathrm{s} ; \\
2000 \text { watts at } 13 \mathrm{~m} / \mathrm{s}\end{array}$ & From 14,016 to 17,520 \\
\hline Stiff wind & $50-61$ & $13.9-17.1$ & $\begin{array}{c}2120 \text { watts at } 14.5 \mathrm{~m} / \mathrm{s} \\
\text { with autonomous } \\
\text { monitoring }\end{array}$ & 18,571 \\
\hline Stormy wind & $62-74$ & $17.2-20.7$ & $\begin{array}{l}2120 \mathrm{~W} \text { autonomously } \\
\text { monitored, with longer } \\
\text { automatic stops }\end{array}$ & 18,571 \\
\hline
\end{tabular}




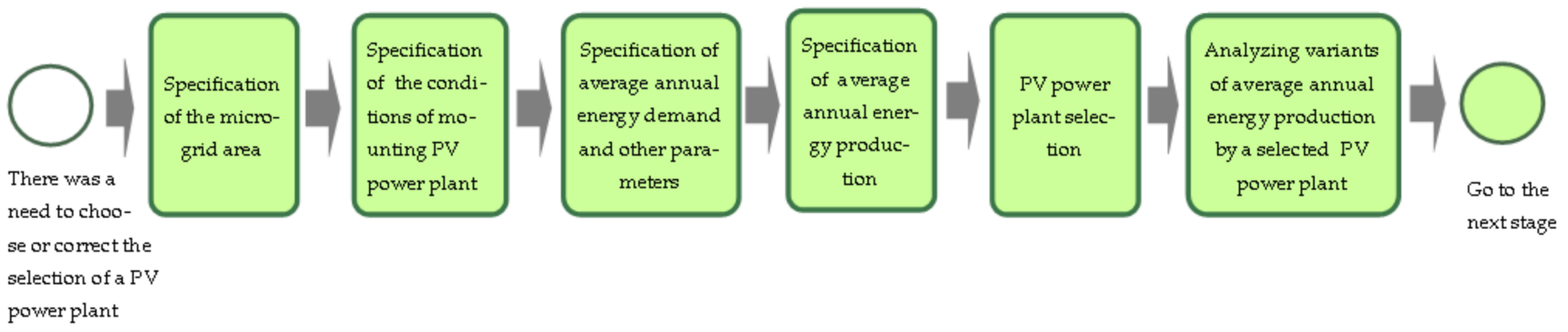

Figure 5. PV power plant selection process.

We determined the average annual energy production and analyzed the conditions for the location of PV panels: the selection of the roof or ground, exposure to the sun, roof pitch, assessment of the strength of the roof truss, and shading of the location. The average PV panel was $1.65 \mathrm{~m}^{2}$, with an average power of $285 \mathrm{~W}$. The power of the PV power plant did not exceed the peak power of the electrical installation to which it was connected. Based on the insolation data of individual regions of the country and the location of PV cells on the south, south-eastern, or south-western sides, we calculated the amount of energy produced. The average insolation of $1300 \mathrm{~W} / \mathrm{m}^{2}$ brings $975 \mathrm{kWh}$ of energy produced per year from one $1 \mathrm{~kW}$ (1000 kWh/year) PV cell. A PV power plant with the capacity of at least $3.1 \mathrm{~kW}$ was needed to cover the annual electric power demand (excluding converter efficiency; PV module efficiency, which varies over the years; and power loss in the energy system). Eleven generating units covering $18 \mathrm{~m}^{2}$ of roof area with the capacity of $285 \mathrm{~W}$ each were necessary to meet the annual electric power demand. Based on the above calculations and considering criteria of sustainable microgrid development, we selected the PV panel Q. PLUS BFR-G4.1 275-285. Table 6 details the relative efficiencies of the panels depending on the insolation (manufacturer's data).

Table 6. Relative efficiency depending on the insolation of the selected PV panels.

\begin{tabular}{cc}
\hline Sunshine $\left[\mathrm{W} / \mathrm{m}^{2}\right]$ & Relative Efficiency [\%] \\
\hline 1000 & 100 \\
\hline 400 & 98 \\
\hline 200 & 96 \\
\hline 100 & 92 \\
\hline
\end{tabular}

Source: developed by the authors based on materials from website [32].

The variability of electric power production in PV power plants was lower than in wind power plants. These two sources complement each other by taking over the power supply of the microgrid if there is a temporary shortage in the supply of wind or solar power. Surplus power produced in specific periods was stored in the energy-storage facility and used in periods of power supply shortage or sold to external clients.

The selection of energy storage is shown in Figure 6. The initial data are the same as in previous sub-processes. 


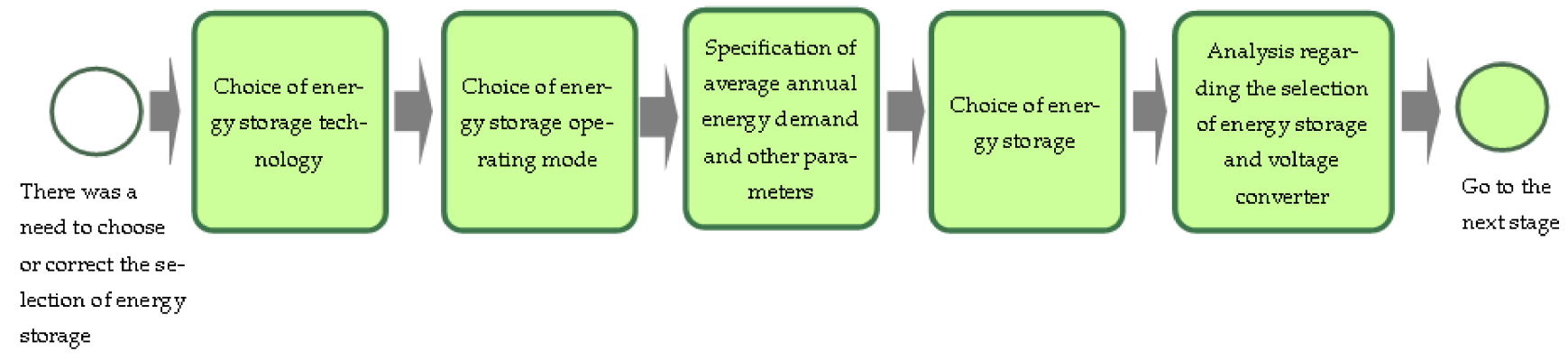

Figure 6. Energy-storage selection process.

We focused on the selection of storage capacity. Based on battery technologies available in the market, we analyzed lead-acid, nickel-cadmium, nickel-hydride, and lithium-ion technologies. Considering sustainable microgrid development, we selected lithium-ion batteries due to their efficiency, charging cycles, and possibility to operate at temperatures below $0{ }^{\circ} \mathrm{C}$. The operating mode of the energy storage was subordinated to sustainability requirements for the microgrid. The electric power supply cycle had a daily pattern, and there was no need to select storage parameters for longer time intervals. Energy storage constituted an additional source of power supply in the evening and at night in the event of temporarily insufficient power supply. In the operation of energy storage, three situations can be observed:

1. Electricity demand is greater than the production capacity of energy sources (wind turbine + PV power plant). The missing power is drawn from energy storage, which is being discharged;

2. RES fully covers the electric power demand, i.e., all power produced is consumed in the microgrid; and

3. Electricity demand is less than production capacity, and surplus power is stored in energy storage.

The third option was preferred, as it allowed the management of surplus stored energy. We adjusted the battery capacity to average 24-h energy consumption:

Energy-storage voltage $=12 \mathrm{~V}$

$$
Q=\frac{Q_{d}}{U+C}=\frac{8900}{12+0.6}=1236 \mathrm{Ah},
$$

where:

$Q_{d}$-daily power demand of the microgrid in [Wh], in this case, $8900 \mathrm{Wh}$;

$U$-battery voltage in [V], assumed to be $12 \mathrm{~V}$; and

$\mathrm{C}$ - permissible degree of discharge, $60 \%$ assumed.

We selected the voltage converter according to the peak power of the microgrid with $10 \%$ reserve for starting currents: $\mathrm{P}=1.1 \times 2.5 \mathrm{~kW}=2.75 \mathrm{~kW} ; 3 \mathrm{~kW}$.

We checked whether a 3-kW converter would limit battery charging with $5 \mathrm{~h}$ of operation:

$$
Q=\frac{P+5}{12}=\frac{3000+5}{12}=1250 \mathrm{Ah}>1236 \mathrm{Ah},
$$

Finally, we selected six parallel-connected batteries with a capacity of 200 Ah each. The batteries were connected in series to increase the voltage of the energy storage and maintain the sustainable operations of our microgrid.

As a result of phase II, a microgrid model dedicated to a selected household was obtained (Figure 7). The description of sub-processes of the (re)design of the infrastructure process enabled the operation of the microgrid in real-life conditions. Moreover, that process aimed to analyze the impact of new elements of the microgrid on the operation of the existing ones to ensure the safety of microgrid ownership boundary. 


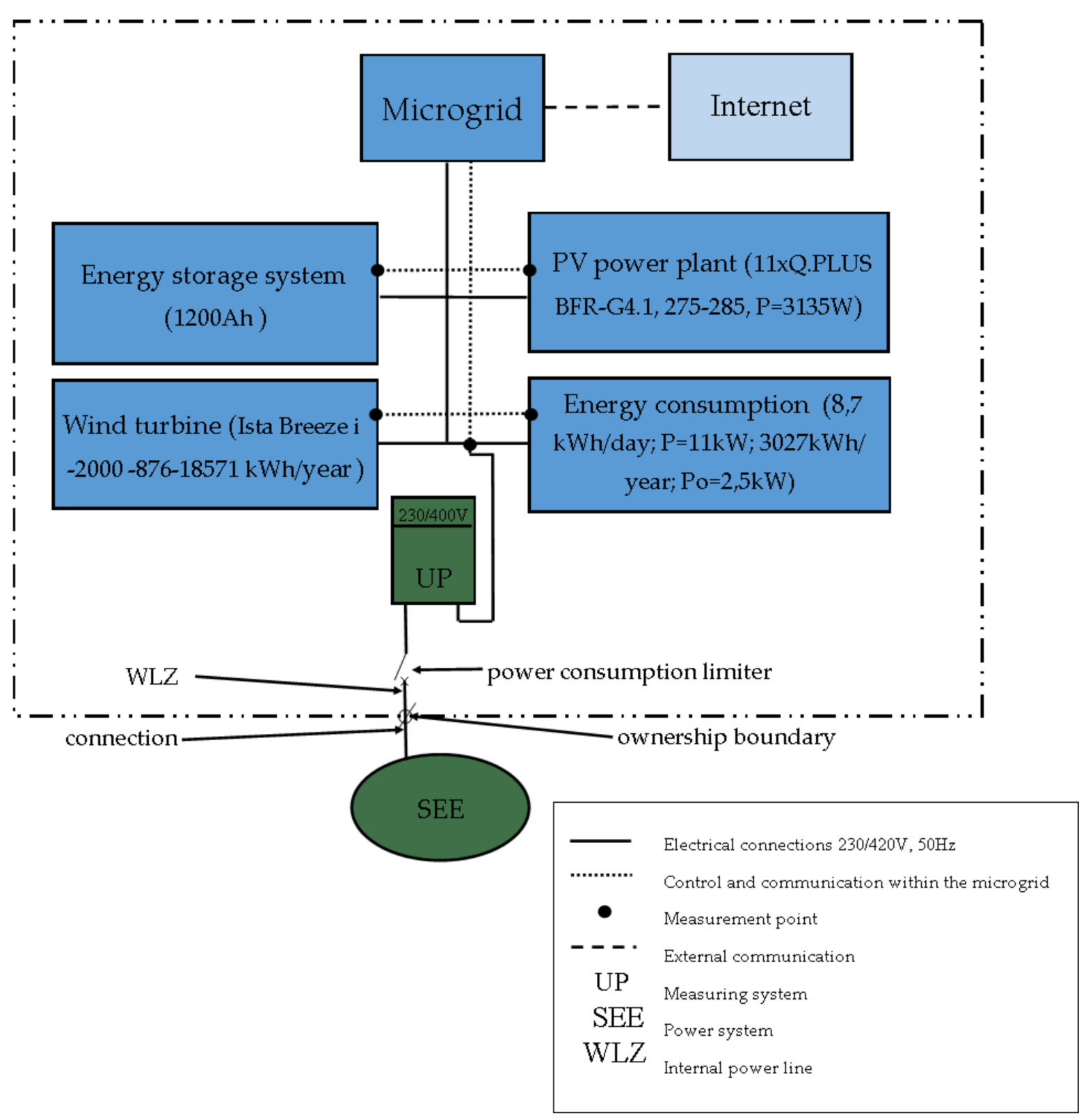

Figure 7. Model of the microgrid dedicated to the selected household.

The specifications selected for the case at hand are provided in parentheses in Figure 7 (the equipment included in Table 1). Overall energy consumption comes from all devices included in Table 1. From the process management point of view, the same process receiving different input parameters will result in different outputs. Although in other micro grid cases the selected devices may have different parameters, the method of their selection will be the same as in this study.

Setting up a dedicated microgrid model in the selected household allowed us to start Phase III-computer simulation of microgrid operation. To verify the correctness of the selection of microgrid elements, a computer model has been created that considers the power demand profiles developed based on the author's own measurements for the working day, holiday, and vacation period, when household members are away from home. Daily changes of demand for active and reactive power for each of the developed profiles are shown in Figures 8 and 9, respectively. 


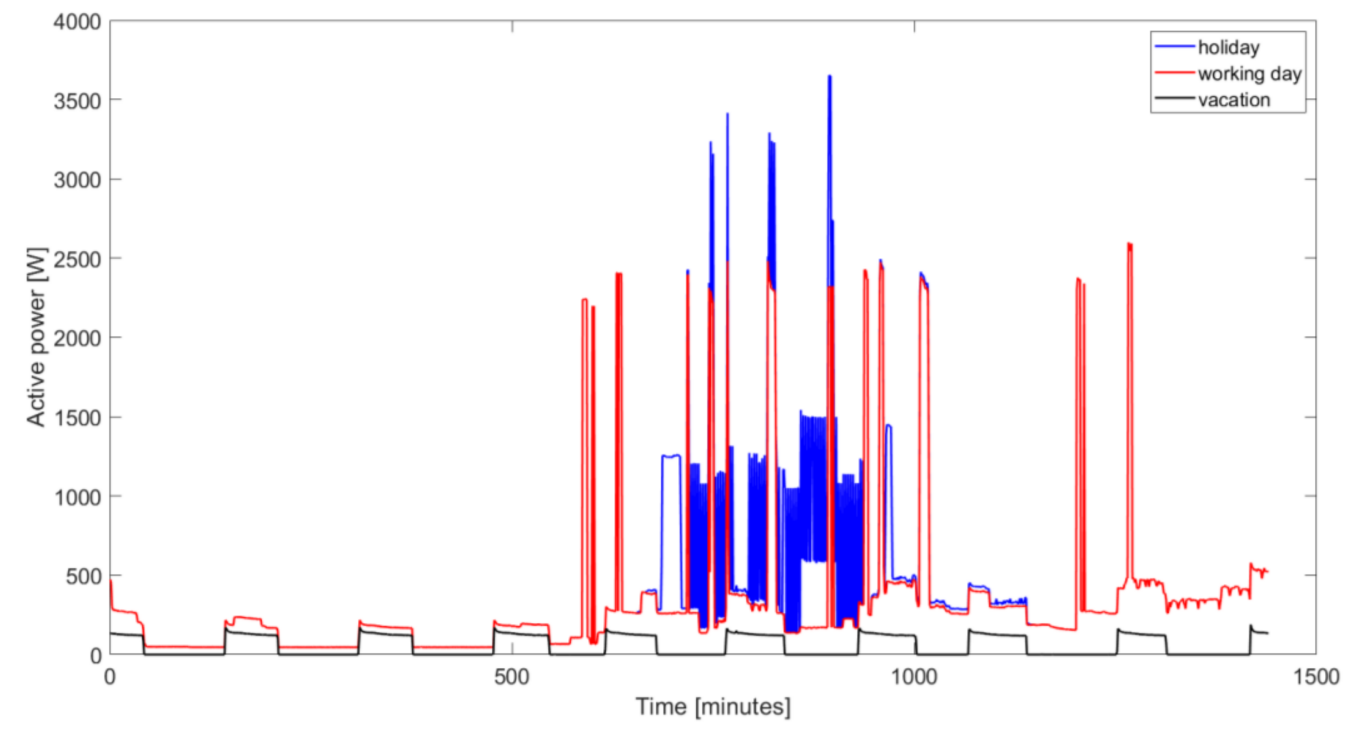

Figure 8. Profiles of daily household demand for active power.

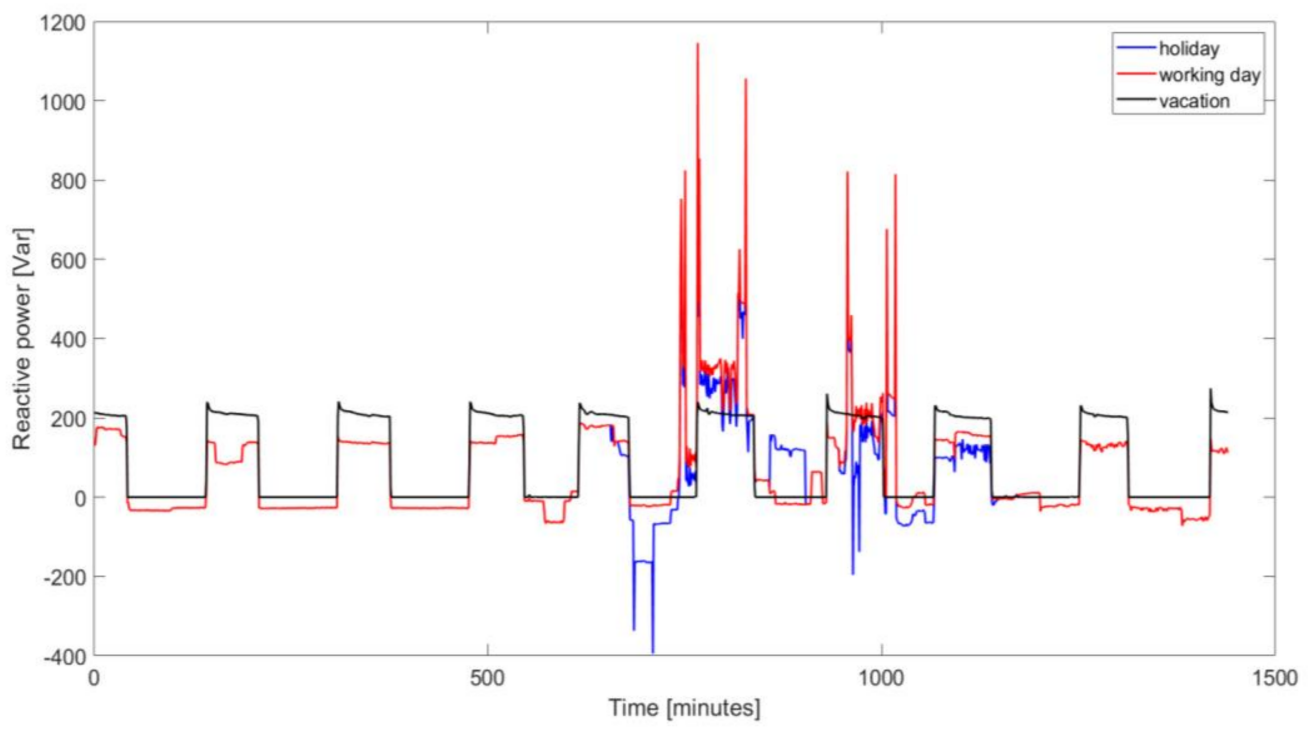

Figure 9. Profiles of daily household demand for reactive power.

To determine the output powers generated by the wind turbine and PV power plant selected in the process of (re)designing microgrid infrastructure, figures on meteorological conditions (wind speed and solar radiation intensity) at the site of the microsources installation were required. Data from [51] were used to determine the profiles of power generated by microsources. The power generated by the wind turbine was calculated based on wind speed and specifications of the turbine provided in Table 4 . Power generated by a PV power plant depends on the intensity of solar radiation, specifications of the PV panels, and the area of exposure. Example profiles of power generated by micro sources are shown in Figure 10. 


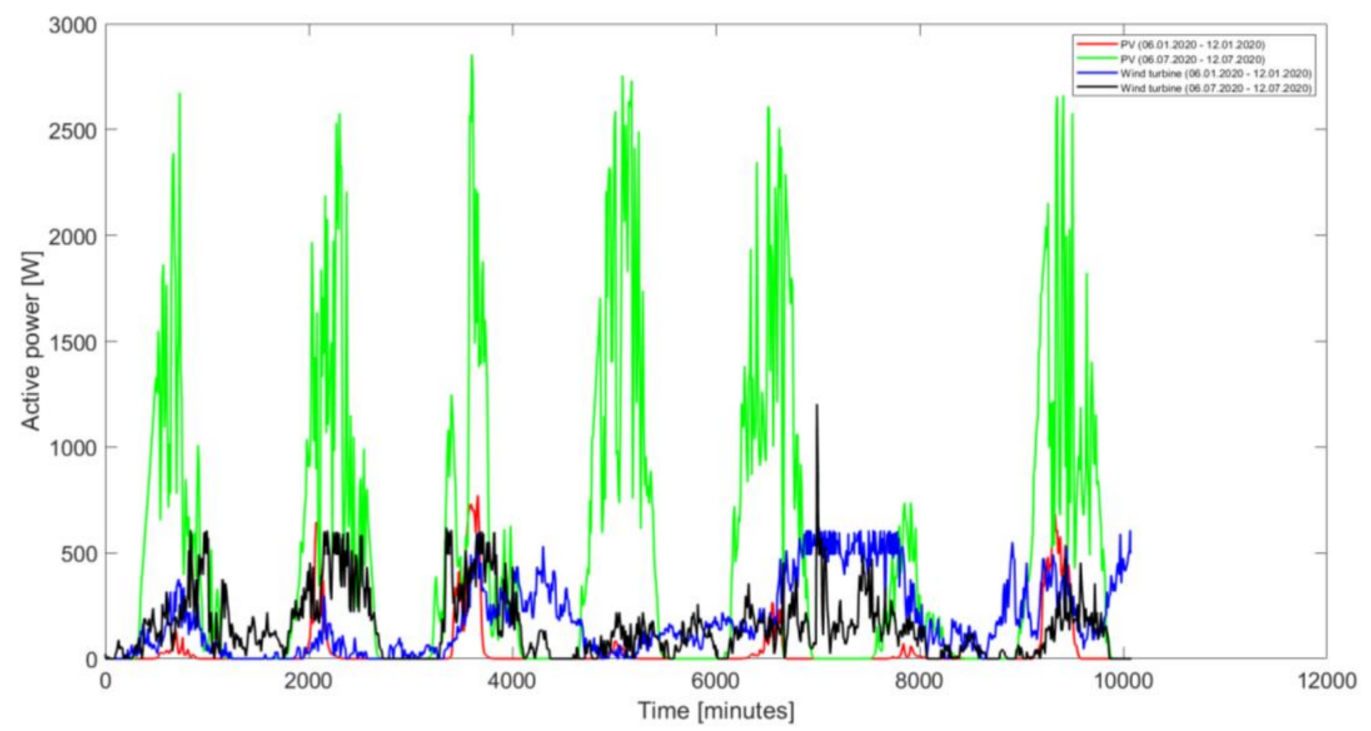

Figure 10. Example profiles of power generated by microsources.

With known generation and power demand profiles, a series of computer simulations of microgrid operation in various time periods was performed to verify correct selection of microgrid elements and the ability of island operation in the long term. Simulation calculations were carried out for each month of 2020 and for the entire year 2020. At the start of the simulation, the SOC of energy-storage device is equal $100 \%$. First it was assumed that the microgrid would be physically disconnected from the distribution grid, and the energy-storage device would be the balancing item. The following constraints are assumed in this part of the simulation:

- when surplus power is generated and SOC of the energy-storage device reaches $100 \%$, microsources will be turned off until the energy-storage device is able to absorb the surplus power;

- if there is a shortage of generated power and at the same time the minimum permissible SOC of energy-storage device is reached, simulation calculations will be interrupted;

- the efficiency of energy-storage device is $80 \%$; and

- three vacation periods are expected to occur on the following dates: 8 February 202023 February 2020, 11 June 2020-14 June 2020, and 1 August 2020-16 August 2020.

The results of simulation calculations in terms of the possibility of long-term island operation of the microgrid, depending on the minimum accepted SOC of energy-storage device are shown in Table 7. Examples of changes in the SOC of energy-storage device are shown in Figure 11.

The simulation calculations carried out show that in the autumn and winter periods, the analyzed microgrid is not able to maintain the island operation without interruptions in the supply of electric power to the consumers installed in the household. The resulting problem can be solved in at least four ways:

1. Install energy storage with greater capacity;

2. Reduce power demand of the household;

3. Provide the microgrid with an additional energy source independent of weather conditions (e.g., a gas microturbine or a power generation set with reciprocating engine), activated in the event of excessive discharge of the energy-storage device; and

4. Connecting the microgrid to the distribution grid while minimizing the importation of electric power from this grid (semi off-grid operation). 
Table 7. Assessment of the potential for long-term island operation of the microgrid depending on the minimum accepted SOC of the energy-storage device.

\begin{tabular}{cccccccc}
\hline \multirow{2}{*}{ Period } & \multicolumn{5}{c}{ Minimum SOC of the Energy-Storage Device [\%] } \\
\cline { 2 - 7 } & $\mathbf{6 0}$ & $\mathbf{5 0}$ & $\mathbf{4 0}$ & $\mathbf{3 0}$ & $\mathbf{2 0}$ & $\mathbf{1 0}$ & 0 \\
\hline January & Not Possible & Not Possible & Not Possible & Not Possible & Not Possible & Not Possible & Not Possible \\
\hline February & Not Possible & Not Possible & Not Possible & Possible & Possible & Possible & Possible \\
\hline March & Not Possible & Not Possible & Not Possible & Not Possible & Not Possible & Not Possible & Not Possible \\
\hline April & Possible & Possible & Possible & Possible & Possible & Possible & Possible \\
\hline May & Not Possible & Possible & Possible & Possible & Possible & Possible & Possible \\
\hline June & Not Possible & Not Possible & Possible & Possible & Possible & Possible & Possible \\
\hline July & Not Possible & Not Possible & Possible & Possible & Possible & Possible & Possible \\
\hline August & Not Possible & Not Possible & Not Possible & Not Possible & Possible & Possible & Possible \\
\hline September & Not Possible & Not Possible & Not Possible & Not Possible & Not Possible & Not Possible & Possible \\
\hline October & Not Possible & Not Possible & Not Possible & Not Possible & Not Possible & Not Possible & Not Possible \\
\hline November & Not Possible & Not Possible & Not Possible & Not Possible & Not Possible & Not Possible & Not Possible \\
\hline December & Not Possible & Not Possible & Not Possible & Not Possible & Not Possible & Not Possible & Not Possible \\
\hline Year & Not Possible & Not Possible & Not Possible & Not Possible & Not Possible & Not Possible & Not Possible \\
\hline
\end{tabular}

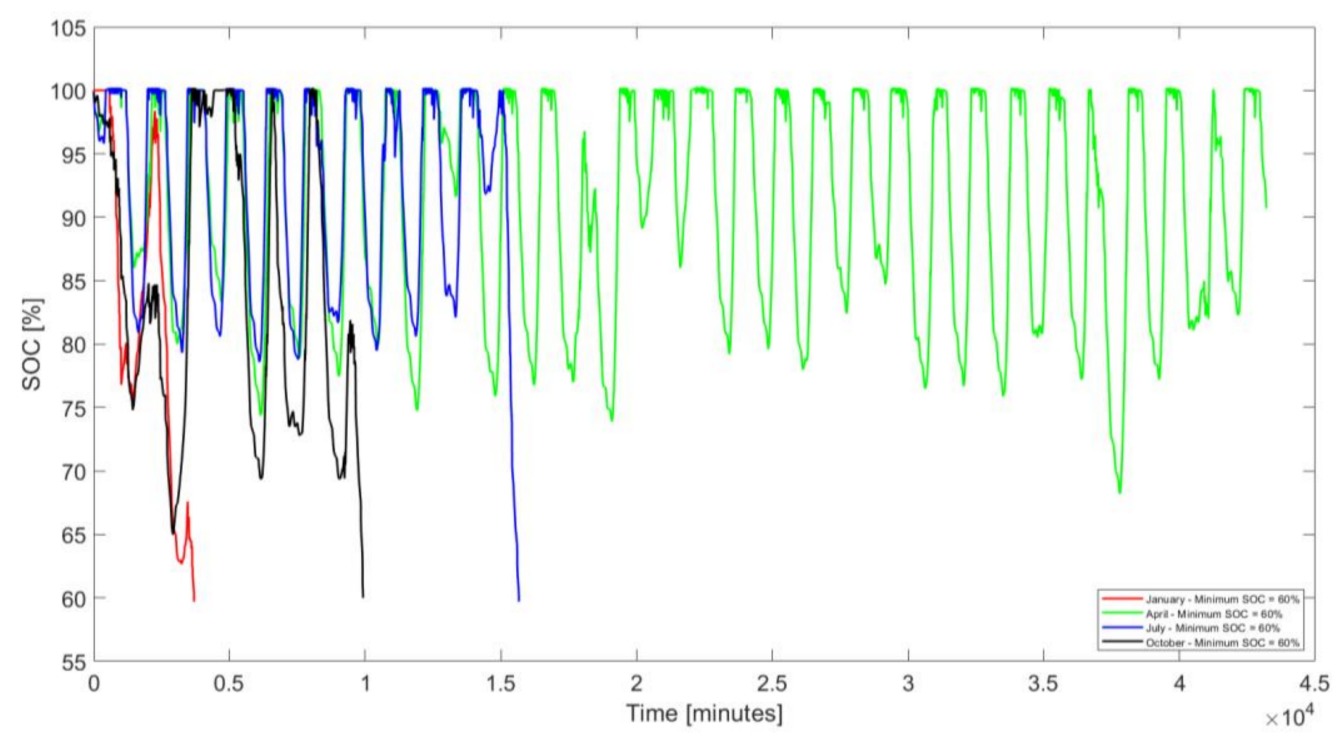

Figure 11. Example changes in the SOC of the energy-storage device in microgrid island operation.

According to the authors, the optimal solution that maximizes the comfort of people living in the household and the potential of using renewable-energy sources, and minimizes the costs incurred, is the operation of microgrid in the semi off-grid mode. In the proposed variant, the microgrid will behave most of the time as if it were in the island mode. The energy-storage device will be controlled in such a way that the balance of electric power exchanged between the microgrid, and the distribution network is zero. If the energystorage device cannot accept surplus power, it will be fed to the distribution network. On the other hand, when the energy-storage device is discharged to the minimum level, the household will be powered from the distribution network. In the financial settlements between the recipient and the distribution network operator, the rules for the billing of electric power prosumers [52] will apply. The application of the provisions contained in [52] means that with the installed power in the microgrid of $5.1 \mathrm{~kW}$, the ratio of power received from the distribution grid to the power fed into the grid is 0.8 . The power balance for the microgrid operating in the semi off-grid mode, depending on the minimum permissible 
SOC of the energy-storage device, is shown in Table 8. Examples of active power flows between the microgrid and the distribution grid are shown in Figure 12.

Table 8. Power balance for the microgrid set up to minimize power importation from the distribution grid depending on the minimum allowed SOC of the energy-storage device.

\begin{tabular}{|c|c|c|c|c|c|c|c|c|c|}
\hline \multirow{2}{*}{ Time Period } & \multicolumn{7}{|c|}{ Minimum SOC of the Energy-Storage Device [\%] } & \multirow{2}{*}{$\begin{array}{c}\text { Without } \\
\text { Energy-Storage Device }\end{array}$} & \multirow{2}{*}{$\begin{array}{c}\text { Without Energy-Storage } \\
\text { Device and } \\
\text { Microsources }\end{array}$} \\
\hline & 60 & 50 & 40 & 30 & 20 & 10 & 0 & & \\
\hline \multirow{3}{*}{ January } & 79.7 & 77.4 & 75.1 & 73.2 & 72.1 & 71.0 & 69.8 & 142.7 & 269.5 \\
\hline & 7.3 & 5.5 & 3.7 & 2.6 & 2.6 & 2.6 & 2.6 & 105.4 & 0.0 \\
\hline & $73.9 *$ & 73.0 & 72.1 & 71.1 & 70.0 & 68.9 & 67.7 & 58.4 & 269.5 \\
\hline \multirow{3}{*}{ February } & 5.9 & 3.6 & 1.3 & 0.5 & 0.5 & 0.5 & 0.5 & 55.4 & 128.9 \\
\hline & 158.6 & 156.7 & 155.0 & 153.7 & 153.7 & 153.7 & 153.7 & 230.4 & 0.0 \\
\hline & 0.0 & 0.0 & 0.0 & 0.0 & 0.0 & 0.0 & 0.0 & 0.0 & 128.9 \\
\hline \multirow{3}{*}{ March } & 22.7 & 20.4 & 18.1 & 15.9 & 14.5 & 13.3 & 12.2 & 116.2 & 261.0 \\
\hline & 112.0 & 108.4 & 104.8 & 101.3 & 99.1 & 97.3 & 95.5 & 255.9 & 0.0 \\
\hline & 0.0 & 0.0 & 0.0 & 0.0 & 0.0 & 0.0 & 0.0 & 0.0 & 261.0 \\
\hline \multirow{3}{*}{ April } & 0.7 & 0.7 & 0.7 & 0.7 & 0.7 & 0.7 & 0.7 & 92.2 & 253.3 \\
\hline & 234.3 & 234.3 & 234.3 & 234.3 & 234.3 & 234.3 & 234.3 & 376.5 & 0.0 \\
\hline & 0.0 & 0.0 & 0.0 & 0.0 & 0.0 & 0.0 & 0.0 & 0.0 & 253.3 \\
\hline \multirow{3}{*}{ May } & 1.2 & 0.8 & 0.8 & 0.8 & 0.8 & 0.8 & 0.8 & 96.5 & 265.3 \\
\hline & 232.8 & 232.2 & 232.2 & 232.2 & 232.2 & 232.2 & 232.2 & 380.2 & 0.0 \\
\hline & 0.0 & 0.0 & 0.0 & 0.0 & 0.0 & 0.0 & 0.0 & 0.0 & 265.3 \\
\hline \multirow{3}{*}{ June } & 1.9 & 0.8 & 0.7 & 0.7 & 0.7 & 0.7 & 0.7 & 83.9 & 221.0 \\
\hline & 278.8 & 277.0 & 276.9 & 276.9 & 276.9 & 276.9 & 276.9 & 404.9 & 0.0 \\
\hline & 0.0 & 0.0 & 0.0 & 0.0 & 0.0 & 0.0 & 0.0 & 0.0 & 221.0 \\
\hline \multirow{3}{*}{ July } & 2.4 & 1.3 & 0.8 & 0.8 & 0.8 & 0.8 & 0.8 & 99.0 & 259.0 \\
\hline & 283.8 & 282.0 & 281.2 & 281.2 & 281.2 & 281.2 & 281.2 & 433.4 & 0.0 \\
\hline & 0.0 & 0.0 & 0.0 & 0.0 & 0.0 & 0.0 & 0.0 & 0.0 & 259.0 \\
\hline \multirow{3}{*}{ August } & 6.4 & 4.1 & 1.8 & 0.5 & 0.5 & 0.5 & 0.5 & 62.4 & 146.7 \\
\hline & 341.3 & 339.6 & 337.8 & 337.4 & 337.4 & 337.4 & 337.4 & 422.1 & 0.0 \\
\hline & 0.0 & 0.0 & 0.0 & 0.0 & 0.0 & 0.0 & 0.0 & 0.0 & 146.7 \\
\hline \multirow{3}{*}{ September } & 8.5 & 6.3 & 5.1 & 4.0 & 2.8 & 1.7 & 0.9 & 119.3 & 251.2 \\
\hline & 85.3 & 83.7 & 83.7 & 83.7 & 83.7 & 83.7 & 83.7 & 252.3 & 0.0 \\
\hline & 0.0 & 0.0 & 0.0 & 0.0 & 0.0 & 0.0 & 0.0 & 0.0 & 251.2 \\
\hline \multirow{3}{*}{ October } & 89.5 & 88.3 & 87.2 & 86.0 & 84.9 & 83.7 & 82.6 & 152.4 & 261.3 \\
\hline & 15.4 & 15.4 & 15.4 & 15.4 & 15.4 & 15.4 & 15.4 & 107.2 & 0.0 \\
\hline & 77.2 & 76.0 & 74.9 & 73.7 & 72.6 & 71.4 & 70.3 & 66.6 & 261.3 \\
\hline \multirow{3}{*}{ November } & 81.2 & 80.1 & 79.0 & 77.8 & 76.7 & 75.5 & 74.4 & 127.4 & 203.6 \\
\hline & 0.2 & 0.2 & 0.2 & 0.2 & 0.2 & 0.2 & 0.2 & 65.5 & 0.0 \\
\hline & 81.0 & 79.9 & 78.8 & 77.6 & 76.5 & 75.3 & 74.2 & 75.0 & 203.6 \\
\hline \multirow{3}{*}{ December } & 91.9 & 89.0 & 87.8 & 86.7 & 85.5 & 84.4 & 83.3 & 142.5 & 261.1 \\
\hline & 27.8 & 25.0 & 25.0 & 25.0 & 25.0 & 25.0 & 25.0 & 100.4 & 0.0 \\
\hline & 69.7 & 69.0 & 67.8 & 66.7 & 65.5 & 64.4 & 63.3 & 62.2 & 261.1 \\
\hline \multirow{3}{*}{ Year } & 411.4 & 396.7 & 385.6 & 376.6 & 369.5 & 362.6 & 355.8 & 1296.2 & 2781.7 \\
\hline & 1756.9 & 1735.6 & 1720.0 & 1707.7 & 1698.4 & 1689.3 & 1680.4 & 3140.8 & 0.0 \\
\hline & 0.0 & 0.0 & 0.0 & 0.0 & 0.0 & 0.0 & 0.0 & 0.0 & 2781.7 \\
\hline
\end{tabular}

* The first value is the power imported from the distribution network, the second value is the power exported to the distribution network, and the third value is the power purchased from the distribution network, considering the rules for prosumer household billing. 


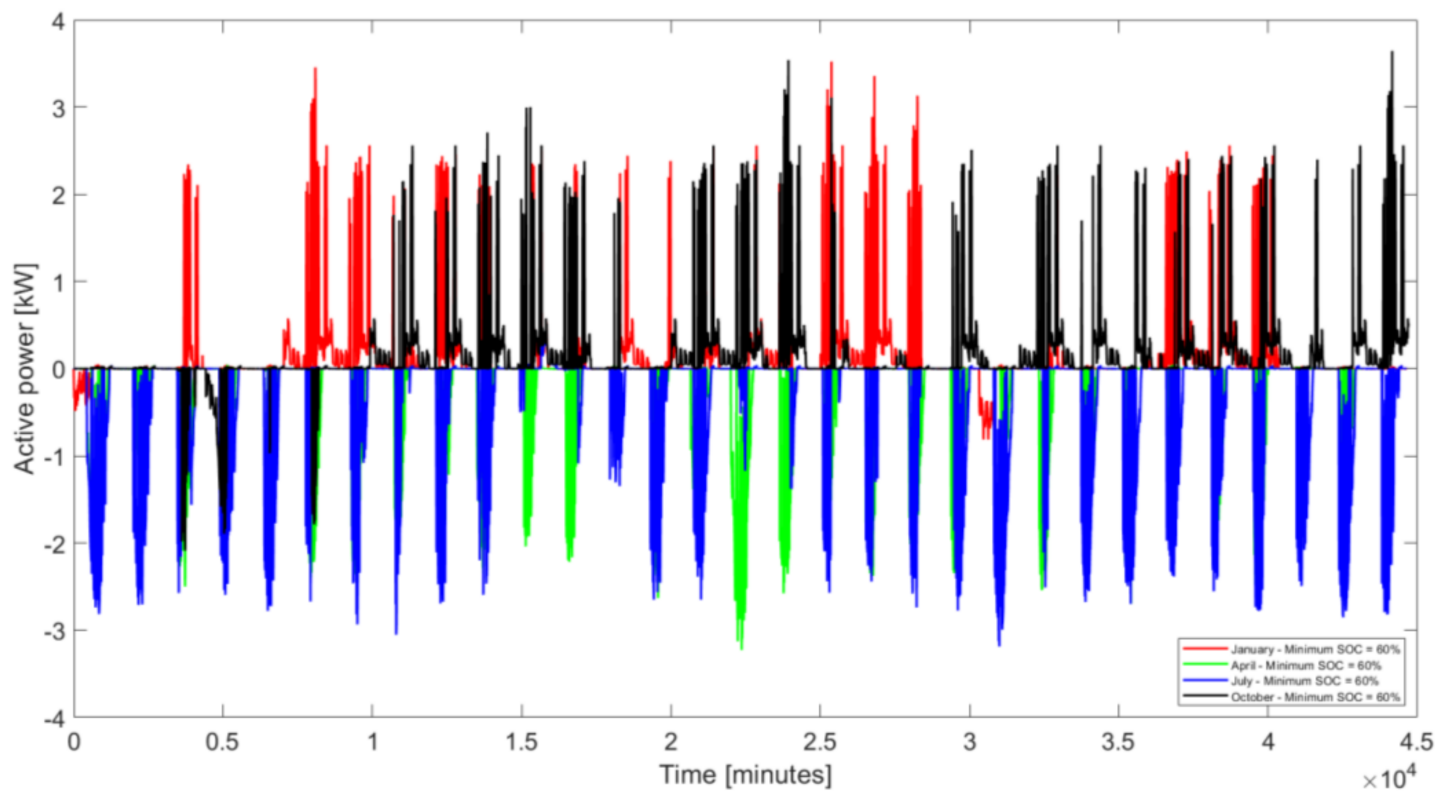

Figure 12. Examples of active power flows between the microgrid and the distribution network (negative values mean exportation of power to the distribution network).

The simulation shows that the microgrid set up to minimize power importation from the distribution grid allows us to minimize the costs of meeting the household's power demand. In the case of monthly billing cycle by the distribution network operator, the consumer will have to purchase electric power only in January and in the fourth quarter of the year. In the case of the annual billing cycle, the purchase of additional power will not be necessary. Given the amount of energy purchased from the distribution grid, it can be concluded that installing an energy-storage device is not cost-effective. However, this conclusion is conditional on current regulations on the amount of free-of-charge power that can be taken from the distribution grid, and it cannot be guaranteed that such regulations will not change to the disadvantage of the consumer. In addition, the loss of mains protections installed in inverters cooperating with microsources force them to be turned off in the event of a power failure in the distribution network. Having your own energy-storage device, equipped with a special island inverter, enables us to operate microsources even in the case of power outage in the distribution grid. Possible increased costs of purchasing power from the distribution grid translate into greater reliability of the microgrid and certainty of supply in emergency situations. Another argument supporting the operation of the microgrid in the semi off-grid mode is the extension of the lifetime of the energy-storage device by setting higher values of the minimum SOC while ensuring $100 \%$ coverage of the consumer's power demand.

\section{Discussion}

This paper studies a scalable microgrid processes model for its massive adoption. We identified eight key processes needed to organize and manage any microgrid: core processes (1. developing technological and organizational infrastructure; 2 . (re)designing of infrastructure; 3 . connecting new sources/loads; 4 . carrying out traffic and power control; 5. cooperating with energy market entities), supporting processes (6. maintaining grid operations; 7. developing human competencies), and management process (8. sustainable energy management). Based on that, a map of these processes and relations among them were developed. Finally, we obtained a scalable microgrid process model, which is sustainable (energy-balanced in a long term). To implement that model of a microgrid, three sub-processes of the (re)design of the infrastructure process were analyzed and structured. Their description allowed the selected microgrid to work in real conditions. We consider 
the set of analytical tools we have prepared to be necessary to scale the microgrid for mass adoption.

This scalable microgrid process model is a novel approach and has not yet been sufficiently explored in literature. Researchers focus on separate microgrid processes without analyzing their impact on other processes in the same microgrid. There are still a limited number of experiments proved to be successful in connecting microgrids to the existing conventional energy system.

Traditional project approaches such as PMO or PRINCE do not work for off-grid household microgrid designs. The traditional approaches are useful for redesigning an existing microgrid to be connected to the DSO network. An effective off-grid microgrid design requires changed design paradigm, for example, using simulation and loopback in the infrastructure (re)design process, to be supported soon by machine learning of a defined task. This is an important condition for microgrid mass adoption, which points to the need for a step-by-step approach to a microgrid fully balanced in the long-term.

Similar to our results, Danish et al. concluded that adequately designed and managed microgrids can support the operation of the conventional distribution network [28]. They proposed a process for managing projects covering the entire life cycle of the microgrid project from kick-off to operation: (1) initiation phase, (2) planning phase, (3) execution phase, (4) monitoring and controlling phase, and (5) closing phase. This approach focuses on properly organizing a sustainable microgrid to ensure its continuity and development in the long term. The approaches adopted by Danish et al. and us are not competitive but complementary to each other: establish an organization and ensure its functioning and improvement in the long term. In addition, the three detailed sub-processes of (1) wind turbine selection, (2) PV power plant selection, and (3) energy-storage selection can complement Phase Two of the microgrid life-cycle presented by Danish et al. [28]. In terms of core processes, Guo et al. $[40,41]$ combined the results of research on connecting new load sources, Pascual [53] focused on developing technological and organizational infrastructure, Okoye et al. [54] focused on designing, and Zhao et al. [55] focused on traffic and power control. As far as supporting processes are concerned, relevant research on maintaining sustainable grid operations was conducted by Hirsch et al. [43]. Finally, the sustainable energy-management process was addressed by Wang et al. [56]. Note that both collaboration with energy market players and developing human competence processes are insufficiently described in the literature. The process model of microgrid organization constitutes a kind of map of microgrid research needs and presents the results obtained in practice.

The results of our research cannot address all the challenges involved in practical functioning of the process model of the sustainable microgrid. Our experiment (phase II) was divided into four stages: 1. initiation stage, or defining the model of the microgrid, its leader/operator and implementing the (re)designing of infrastructure process; 2 . connecting to the DSO distribution network (grid) to provide the necessary power reserves; 3. connecting to the DSO distribution network (grid) in such a way that disconnection from the DSO network does not deteriorate the electric power quality indicators; and 4. establishing a microgrid as a fully autonomous and sustainable off-grid system disconnected from the DSO distribution network. We have completed the first stage and confirmed the correctness of our microgrid design by conducting a computer simulation of its operation (Phase III). Implementation of the other three stages will lead to establishing a microgrid as a sustainable system by applying proper technology, organization, and management. Such a microgrid would be a ready template for mass adoption, enabling the development of both knowledge and legislation to facilitate cooperation between DSOs, investors, and microgrid local owners.

Conducting further experiments is necessary for the implementation of a sustainable microgrid model in practice on a mass scale. It is difficult to predict how the grid will behave with a large quantity of connected RES equipment, energy-storage facilities, and electric cars, with small cable cross-sections and long circuits. The operation, control, and 
shock protection of the distribution grid with mass connection of microgrids raises five significant challenges that should be further investigated. The first is bidirectional power flow, where it is necessary to look for ways to "stop" power at a given voltage level. What is necessary is massive use of energy-storage facilities and simple rules for their selection that can be understood by the ordinary consumer, as well as incentives for investors to use them in their power plants. The second challenge is the short-circuit efficiency, which in the case of typically distributed generation converters limits the short-circuit current to a maximum of twice the rated current. Therefore, more short-circuit-proof converters are needed to prepare for island operation, as is proper functioning of the mass protection of electrical installations of buildings. The third challenge is voltage instability that can arise due to interactions between the power system and microgrids. This applies to microgrids that are "electrically distant" from the power station that stabilizes the voltage in the grid. It is necessary to identify ways to control adequate low-voltage grid operating conditions. The fourth challenge concerns a low inertia of the system based on distributed sources, caused by low power and dispersion of the generating sources. This can cause large frequency deviations in the island operation mode. The fifth challenge is the uncertainty of the operation of the sources due to their properties: dependence on climatic factors (sun or wind).

The knowledge gained in this exercise can be used for redevelopment of the existing processes of the distribution grid service organization (including its parts operating within the microgrid and on its interfaces) and the extensive training of people to prepare them for new challenges.

\section{Conclusions}

The primary purpose of the work was to fill an existing gap regarding the operation model of microgrids that is a barrier for the large-scale integration of those in the conventional grid network. For solving this situation, the authors identified key processes to be considered when operating microgrids, in the conditions shown through an experimental (simulation) campaign. The development of a scalable process model of microgrids required performing the adequate research tasks. New contributions of this paper can be summarized as follows:

1. Finalizing the description of eight key processes for designing a microgrid process map;

2. Development of a scalable microgrid process model;

3. Presentation of laboratory experimental results;

4. Presentation of the results of computer simulations that have validated the robust-ness of our model; and

5. Discussion and evaluation of the results according to a scalable microgrid process model.

Our contribution is in line with (Schlesinger et al., 1979) [57] approach. The validation of the simulation model confirmed that it is a sufficiently accurate representation of the conceptual microgrid process model. It was indicated and widely supported in Section 4. Nevertheless, the validation process is permanent (it lasts from the moment the assumptions for the model are formulated to the end of its operation). The microgrid is a critical link in the sustainable development of the new generation of electric power systems. Its autonomous nature contributes to reducing interference and strengthening grid resistance. The process model of the sustainable microgrid can act as a controlled consumer and controlled generator. The next research step will be to outline a concise, step-by-step process for developing a scaling-up strategy. The rationale behind such a research undertaking is twofold. First, strategic planning for the expansion and institutionalization of successfully tested operating microgrid is essential, but in practice often does not happen. As a result, effective new practices and technology advances remain underutilized. It is hoped that the availability of the real-world, validated process microgrid model will encourage broader attention to systematic planning once pilot microgrid have been successfully tested. 
Author Contributions: Conceptualization, S.S.-R., G.K., L.H. and S.R.; methodology, S.S.-R. and G.K.; validation, G.K. and Ł.R.; formal analysis, S.S.-R., G.K., Ł.R. and S.R.; investigation, S.S.-R., G.K. and Ł.R.; resources, G.K., Ł.R. and S.R.; data curation, G.K. and Ł.R.; writing-original draft preparation, S.S.-R., G.K. and L.H.; writing-review and editing, S.S.-R., G.K., L.H., Ł.R. and S.R.; visualization, G.K. and L.H.; supervision, S.S.-R.; project administration, G.K. All authors have read and agreed to the published version of the manuscript.

Funding: This research was funded by Warsaw University of Technology (Poland), grant number RDN-49/I/2020.

Institutional Review Board Statement: Not applicable.

Informed Consent Statement: Not applicable.

Data Availability Statement: Datasets related to this article will be available in an open-source online data repository hosted at Mendeley Data after final submission (https: / data.mendeley.com/ drafts/wdztx7njv4 (available on 25 August 2021)).

Conflicts of Interest: The authors declare no conflict of interest.

\section{Appendix A}

Highly cited papers (microgrid in the title).

\begin{tabular}{|c|c|c|}
\hline No. & Times Cited (WoS) & Paper \\
\hline 1 & 1473 & $\begin{array}{l}\text { Pogaku N, Prodanović M, and Green TC. Modeling, analysis and testing of autonomous operation } \\
\text { of an inverter-based microgrid. IEEE Transactions on Power Electronics 2007;22. } \\
\text { https:// doi.org/10.1109/TPEL.2006.890003 }\end{array}$ \\
\hline 2 & 1265 & $\begin{array}{l}\text { Olivares DE, Mehrizi-Sani A, Etemadi AH, Cañizares CA, Iravani R, Kazerani M, et al. Trends in } \\
\text { microgrid control. IEEE Transactions on Smart Grid 2014;5. } \\
\text { https:/ / doi.org/10.1109/TSG.2013.2295514 }\end{array}$ \\
\hline 3 & 947 & $\begin{array}{l}\text { Katiraei F, and Iravani MR. Power management strategies for a microgrid with multiple distributed } \\
\text { generation units. IEEE Transactions on Power Systems 2006;21. } \\
\text { https: / / doi.org/10.1109/TPWRS.2006.879260 }\end{array}$ \\
\hline 4 & 828 & $\begin{array}{l}\text { Lasseter RH, and Paigi P. Microgrid: A conceptual solution. PESC Record - IEEE Annual Power } \\
\text { Electronics Specialists Conference, vol. 6, 2004. https://doi.org/10.1109/PESC.2004.1354758 }\end{array}$ \\
\hline 5 & 713 & $\begin{array}{l}\mathrm{Li} \mathrm{YW} \text {, and Kao CN. An accurate power control strategy for power-electronics-interfaced } \\
\text { distributed generation units operating in a low-voltage multibus microgrid. IEEE Transactions on } \\
\text { Power Electronics 2009;24. https:// doi.org/10.1109/TPEL.2009.2022828 }\end{array}$ \\
\hline 6 & 640 & $\begin{array}{l}\text { Liu X, Wang P, and Loh PC. A hybrid AC/DC microgrid and its coordination control. IEEE } \\
\text { Transactions on Smart Grid 2011;2. https:// doi.org/10.1109/TSG.2011.211616 }\end{array}$ \\
\hline 7 & 600 & $\begin{array}{l}\text { Kanchev H, Lu D, Colas F, Lazarov V, and Francois B. Energy management and operational } \\
\text { planning of a microgrid with a PV-based active generator for smart grid applications. IEEE } \\
\text { Transactions on Industrial Electronics 2011;58. https://doi.org/10.1109/TIE.2011.2119451 }\end{array}$ \\
\hline 8 & 586 & $\begin{array}{l}\text { Dimeas AL, and Hatziargyriou ND. Operation of a multiagent system for microgrid control. IEEE } \\
\text { Transactions on Power Systems 2005;20. https:/ / doi.org/10.1109/TPWRS.2005.852060 }\end{array}$ \\
\hline 9 & 568 & $\begin{array}{l}\text { Kakigano H, Miura Y, and Ise T. Low-voltage bipolar-type dc microgrid for super high quality } \\
\text { distribution. IEEE Transactions on Power Electronics 2010;25. } \\
\text { https: / / doi.org/10.1109/TPEL.2010.2077682 }\end{array}$ \\
\hline 10 & 562 & $\begin{array}{l}\text { Chen C, Duan S, Cai T, Liu B, and Hu G. Smart energy management system for optimal microgrid } \\
\text { economic operation. IET Renewable Power Generation 2011;5. } \\
\text { https:/ / doi.org/10.1049/iet-rpg.2010.0052 }\end{array}$ \\
\hline
\end{tabular}




\section{References}

1. McCauley, D. Sustainable Development in Energy Policy: A Governance Assessment of Environmental Stakeholder Inclusion in Waste-to-Energy. Sustain. Dev. 2015, 23, 273-284. [CrossRef]

2. Siksnelyte, I.; Zavadskas, E.K. Achievements of the European Union Countries in Seeking a Sustainable Electricity Sector. Energies 2019, 12, 2254. [CrossRef]

3. International Renewable Energy Agency (IRENA). Renewable Power-to-Hydrogen Innovation Landscape Brief; Irena: Abu Dhabi, United Arab Emirates, 2019.

4. Hurtt, J.; Mili, L. Residential microgrid model for disaster recovery operations. In Proceedings of the 2013 IEEE Grenoble Conference PowerTech, POWERTECH, Grenoble, France, 16-20 June 2013.

5. Rahbar, K.; Chai, C.C.; Zhang, R. Energy Cooperation Optimization in Microgrids with Renewable Energy Integration. IEEE Trans. Smart Grid 2016, 9, 1482-1493. [CrossRef]

6. Justo, J.J.; Mwasilu, F.; Lee, J.; Jung, J.-W. AC-microgrids versus DC-microgrids with distributed energy resources: A review. Renew. Sustain. Energy Rev. 2013, 24, 387-405. [CrossRef]

7. Available online: https:/ / certs.lbl.gov / publications?page=32 (accessed on 21 October 2021).

8. Mengelkamp, E.; Gärttner, J.; Rock, K.; Kessler, S.; Orsini, L.; Weinhardt, C. Designing microgrid energy markets: A case study: The Brooklyn Microgrid. Appl. Energy 2018, 210, 870-880. [CrossRef]

9. Lopes, J.A.P.; Madureira, A.G.; Moreira, C.C.L.M. A view of microgrids. Wiley Interdisciplinary Reviews: Energy and Environment. Wiley Interdiscip. Rev. Energy Environ. 2017, 2, 86-103. [CrossRef]

10. Mumtaz, F.; Bayram, I.S. Planning, Operation, and Protection of Microgrids: An Overview. Energy Procedia 2017, 107, 94-100. [CrossRef]

11. Alegria, E.; Brown, T.; Minear, E.; Lasseter, R.H. CERTS Microgrid Demonstration with Large-Scale Energy Storage and Renewable Generation. IEEE Trans. Smart Grid 2013, 5, 937-943. [CrossRef]

12. Dobson-Lohman, E. Artificial Intelligence-based Decision-Making Algorithms, Internet of Things Smart Devices, and Real-Time Process Monitoring in Sustainable Industry 4.0. Econ. Manag. Financial Mark. 2020, 15, 30. [CrossRef]

13. Kamble, S.S.; Gunasekaran, A.; Gawankar, S.A. Sustainable Industry 4.0 framework: A systematic literature review identifying the current trends and future perspectives. Process. Saf. Environ. Prot. 2018, 117, 408-425. [CrossRef]

14. Rashid, M.M.U.; Alotaibi, M.A.; Chowdhury, A.H.; Rahman, M.; Alam, M.S.; Hossain, M.A.; Abido, M.A. Home Energy Management for Community Microgrids Using Optimal Power Sharing Algorithm. Energies 2021, 14, 1060. [CrossRef]

15. Weston, P.; Kalhoro, W.; Lockhart, E.; Reber, T.; Booth, S. Financial and Operational Bundling Micro-Grid Business Models; National Renewable Energy Lab. (NREL): Golden, CO, USA, 2018.

16. Ali, A.; Li, W.; Hussain, R.; He, X.; Williams, B.W.; Memon, A.H. Overview of Current Microgrid Policies, Incentives and Barriers in the European Union, United States and China. Sustainability 2017, 9, 1146. [CrossRef]

17. Microgrid Portfolio of Activities (USA). Available online: https://www.energy.gov/oe/microgrid-portfolio-activities (accessed on 21 October 2021).

18. Asmus, P.; Rodrigues Labastidia, R. How Utilities Can Be Microgrid Leaders, PXiSE Energy Solutions; Guidehouse Inc.: Chicago, IL, USA, 2020.

19. Van Acker, V.; Szablya, S.J.; Louie, H.; McLean Sloughter, J.; Pirbhai, A.S. Survey of energy use and costs in rural Kenya for community microgrid business model development. In Proceedings of the Proceedings of the 4th IEEE Global Humanitarian Technology Conference, GHTC 2014, San Jose, CA, USA, 10-13 October 2014.

20. Al Faruque, M.A. RAMP: Impact of rule based aggregator business model for residential microgrid of prosumers including distributed energy resources. In Proceedings of the 2014 IEEE PES Innovative Smart Grid Technologies Conference, ISGT 2014, Washington, DC, USA, 19-22 February 2014.

21. Hanna, R.; Disfani, V.R.; Kleissl, J.; Victor, D.G. A new simulation model to develop and assess business cases for commercial microgrids. In Proceedings of the 2017 North American Power Symposium, NAPS 2017, Morgantown, WV, USA, 17-19 September 2017.

22. Dibaba, H.; Vanadzina, E.; Mendes, G.; Pinomaa, A.; Honkapuro, S. Business Model Design for Rural Off-the-Grid Electrifi-cation and Digitalization Concept. In Proceedings of the International Conference on the European Energy Market, EEM, Stockholm, Sweden, 16-18 September 2020.

23. Vanadzina, E.; Mendes, G.; Honkapuro, S.; Pinomaa, A.; Melkas, H. Business models for community microgrids. In Proceedings of the International Conference on the European Energy Market, EEM, Ljubljana, Slovenia, 18-20 September 2019.

24. Sanz, J.F.; Matute, G.; Bludszuweit, H.; Laporta, E. Microgrids, a new business model for the energy market. Renew. Energy Power Qual. J. 2014, 868-873. [CrossRef]

25. Sajjad, I.A.; Napoli, R.; Chicco, G. Future business model for cellular microgrids. In Proceedings of the BMSD 2014-4th International Symposium on Business Modeling and Software Design, Luxembourg, 24-26 June 2014.

26. Porter, M.E. Competitive Advantage. Creating and Sustaining Superior Performance; The Free Press: New York, NY, USA, 1998; ISBN 0684841460.

27. Priya, T.M.; Sanjana, V.; Gohila, B.; Lavanya, R.; Anbazhagan, A.; Veerasundaram, M.; Ramesh, L. Design and Analysis of a Sustainable LV Residential Microgrid. Procedia Technol. 2015, 21, 139-146. [CrossRef] 
28. Shah Danish, M.S.; Senjyu, T.; Funabashia, T.; Ahmadi, M.; Ibrahimi, A.M.; Ohta, R.; Rashid Howlader, H.O.; Zaheb, H.; Sabory, N.R.; Sediqi, M.M. A sustainable microgrid: A sustainability and management-oriented approach. Energy Procedia 2019, 159, 160-167. [CrossRef]

29. Aberilla, J.M.; Gallego-Schmid, A.; Stamford, L.; Azapagic, A. Design and environmental sustainability assessment of small-scale off-grid energy systems for remote rural communities. Appl. Energy 2019, 258, 114004. [CrossRef]

30. Pogaku, N.; Prodanovic, M.; Green, T. Modeling, Analysis and Testing of Autonomous Operation of an Inverter-Based Microgrid. IEEE Trans. Power Electron. 2007, 22, 613-625. [CrossRef]

31. Olivares, D.E.; Mehrizi-Sani, A.; Etemadi, A.H.; Canizares, C.A.; Iravani, R.; Kazerani, M.; Hajimiragha, A.H.; Gomis-Bellmunt, O.; Saeedifard, M.; Palma-Behnke, R.; et al. Trends in Microgrid Control. IEEE Trans. Smart Grid 2014, 5, 1905-1919. [CrossRef]

32. Katiraei, F.; Iravani, M. Power Management Strategies for a Microgrid with Multiple Distributed Generation Units. IEEE Trans. Power Syst. 2006, 21, 1821-1831. [CrossRef]

33. Lasseter, R.H.; Paigi, P. Microgrid: A conceptual solution. In Proceedings of the PESC Record-IEEE Annual Power Electronics Specialists Conference, Aachen, Germany, 20-25 June 2004.

34. Li, Y.W.; Kao, C.-N. An Accurate Power Control Strategy for Power-Electronics-Interfaced Distributed Generation Units Operating in a Low-Voltage Multibus Microgrid. IEEE Trans. Power Electron. 2009, 24, 2977-2988. [CrossRef]

35. Liu, X.; Wang, P.; Loh, P.C. A Hybrid AC/DC Microgrid and Its Coordination Control. IEEE Trans. Smart Grid 2011, 2, 278-286. [CrossRef]

36. Kanchev, H.; Lu, D.; Colas, F.; Lazarov, V.; Francois, B. Energy Management and Operational Planning of a Microgrid with a PV-Based Active Generator for Smart Grid Applications. IEEE Trans. Ind. Electron. 2011, 58, 4583-4592. [CrossRef]

37. Dimeas, A.L.; Hatziargyriou, N.D. Operation of a Multiagent System for Microgrid Control. IEEE Trans. Power Syst. 2005, 20, 1447-1455. [CrossRef]

38. Kakigano, H.; Miura, Y.; Ise, T. Low-Voltage Bipolar-Type DC Microgrid for Super High Quality Distribution. IEEE Trans. Power Electron. 2010, 25, 3066-3075. [CrossRef]

39. Chen, C.; Duan, S.; Cai, T.; Liu, B.; Hu, G. Smart energy management system for optimal microgrid economic operation. IET Renew. Power Gener. 2011, 5, 258-267. [CrossRef]

40. Guo, S.; Zhao, H.; Zhao, H. The Most Economical Mode of Power Supply for Remote and Less Developed Areas in China: Power Grid Extension or Micro-Grid? Sustainability 2017, 9, 910. [CrossRef]

41. Niu, M.; Huang, W.; Guo, J.; Su, L. Research on economic operation of grid-connected microgrid. Power Syst. Technol. 2010, 34, 38-42.

42. Pecenak, Z.K.; Stadler, M.; Fahy, K. Efficient multi-year economic energy planning in microgrids. Appl. Energy 2019, $255,113771$. [CrossRef]

43. Hirsch, A.; Parag, Y.; Guerrero, J. Microgrids: A review of technologies, key drivers, and outstanding issues. Renew. Sustain. Energy Rev. 2018, 90, 402-411. [CrossRef]

44. Saffari, M.; de Gracia, A.; Fernández, C.; Belusko, M.; Boer, D.; Cabeza, L.F. Optimized demand side management (DSM) of peak electricity demand by coupling low temperature thermal energy storage (TES) and solar PV. Appl. Energy 2018, 211, 604-616. [CrossRef]

45. Jin, X.; Wu, J.; Mu, Y.; Wang, M.; Xu, X.; Jia, H. Hierarchical microgrid energy management in an office building. Appl. Energy 2017, 208, 480-494. [CrossRef]

46. Jin, M.; Feng, W.; Liu, P.; Marnay, C.; Spanos, C. MOD-DR: Microgrid optimal dispatch with demand response. Appl. Energy 2017, 187, 758-776. [CrossRef]

47. Schram, W.L.; Lampropoulos, I.; van Sark, W.G.J.H.M. Photovoltaic systems coupled with batteries that are optimally sized for household self-consumption: Assessment of peak shaving potential. Appl. Energy 2018, 223, 69-81. [CrossRef]

48. Rodriguez-Diaz, E.; Palacios-Garcia, E.J.; Anvari-Moghaddam, A.; Vasquez, J.C.; Guerrero, J.M. Real-time Energy Management System for a hybrid AC/DC residential microgrid. In Proceedings of the 2017 IEEE 2nd International Conference on Direct Current Microgrids, ICDCM 2017, Nuremburg, Germany, 27-29 June 2017.

49. LLindh, C.; Nordman, E.R. New Service Development and Digitalization: Synergies of Personal Interaction and IT Integration. Serv. Mark. Q. 2018, 39, 108-123. [CrossRef]

50. Sysko-Romańczuk, S.; Kluj, G. Mikrosieci jako innowacyjny komponent dywersyfikacji rynku energetycznego w Polsce. Przeglad Organ. 2019, 31, 19-24. [CrossRef]

51. Internetowa Stacja Meteo Warszawa I Pogoda on-line (in Polish). Available online: http:/ /www.meteo.waw.pl (accessed on 25 August 2021).

52. The Act of February 20, 2015 on Renewable Energy Sources, Journal of Laws 2015 item 478. Available online: http:/ /isap.sejm. gov.pl/isap.nsf/DocDetails.xsp?id=wdu20150000478 (accessed on 25 August 2021).

53. Pascual, J.; Barricarte, J.; Sanchis, P.; Marroyo, L. Energy management strategy for a renewable-based residential microgrid with generation and demand forecasting. Appl. Energy 2015, 158, 12-25. [CrossRef]

54. Okoye, C.O.; Oranekwu-Okoye, B.C. Economic feasibility of solar PV system for rural electrification in Sub-Sahara Africa. Renew. Sustain. Energy Rev. 2018, 82, 2537-2547. [CrossRef] 
55. Zhao, Z.; Lee, W.C.; Shin, Y.; Song, K. An Optimal Power Scheduling Method Applied in Home Energy Management System Based on Demand Response. ETRI J. 2013, 35, 677-686. [CrossRef]

56. Wang, F.; Zhou, L.; Ren, H.; Liu, X. Search improvement process-chaotic optimization-particle swarm optimization-elite retention strategy and improved combined cooling-heating-power strategy based. Energies 2017, 10, 1936. [CrossRef]

57. Schlesinger, S. Terminology for model credibility. SIMULATION 1979, 32, 103-104. [CrossRef] 